\title{
Religious fragmentation, social identity and cooperation: Evidence from an artefactual field experiment in India*
}

\author{
Surajeet Chakravarty, Miguel A. Fonseca, Sudeep Ghosh and Sugata Marjit
}

December 19, 2015

\begin{abstract}
We study the role of village-level religious fragmentation on intra- and inter-group cooperation in India. We report on data on two-player Prisoners' Dilemma and Stag Hunt experiments played by 516 Hindu and Muslim participants in rural India. Our treatments are the identity of the two players and the degree of village-level religious heterogeneity. In religiously-heterogeneous villages, cooperation rates in the Prisoners' Dilemma, and to a lesser extent the Stag Hunt game, are higher when subjects of either religion play with a fellow in-group member than when they play with an out-group member or with someone whose identity is unknown. Interestingly, cooperation rates among people of the same religion are significantly lower in homogeneous villages than in fragmented villages in both games.
\end{abstract}

JEL - classification numbers: C93, D03, H41

Keywords: Social Identity, Social Fragmentation, Artefactual Field Experiment.

\footnotetext{
${ }^{*}$ Chakravarty: University of Exeter; Email: s.chakravarty@exeter.ac.uk. Fonseca: University of Exeter; Email: m.a.fonseca@exeter.ac.uk. Ghosh: Hong Kong Polytechnic University; Email: afsghosh@polyu.edu.hk; Marjit: Center for Studies in the Social Sciences, Calcutta, marjit@gmail.com. We gratefully acknowledge financial support from the ESRC grant ES/J018643/1. We thank Jharna Phanda, Sujit Kumar Mondal, Ramkrishna Mondal, Naresh Chandra Mondal, Sk.Md. Basiruddin for their excellent assistance with running the sessions. We thank two anonymous referees and the editors, in addition to Avner Ben-Ner, Martin Leroch, Pushkar Maitra, Kim Peters, Rohini Somanathan, Daniel Zizzo, participants at the 2015 SAET conference at U. of Cambridge, the 2014 THEEM workshop at the U. of Konstanz, and the Identity, Public Goods and Development workshop at CSSS Kolkata, as well as seminars at U. of Durham, U. of Exeter, U. of Middlesex, Monash U., HEC Lausanne, and U. of Paderborn for helpful comments and suggestions. All errors are ours alone. We have obtained approval to conduct this research from the ethics officer (IRB-equivalent) at the University of Exeter.
} 


\section{Introduction}

Economists have established over the last two decades a negative relationship between social fragmentation (typically defined as a function of the relative size of different social groups in the population) and economic performance, in particular public good provision (Easterly and Levine, 1999; Alesina et al., 1999, 2003; Alesina and La Ferrara, 2005; Banerjee et al., 2005). There are many possible reasons for this negative relationship: different social groups may prefer different types of public goods (Poterba, 1998); restricting economic transactions to within a group may also be useful as it reduces informational asymmetries, and increases the scope for the punishment of transgressors (Greif, 1993; Miguel and Gugerty, 2005). Finally, individuals may prefer to share a public good with those of their own group and/or dislike sharing a public good with people from other social groups (Alesina and La Ferrara, 2005).

We study the effect of village-level religious fragmentation on intra- and inter-group cooperation. We are particularly interested in understanding the role religious identity plays in explaining behavior in two classic cooperation games. These games feature incentive structures relevant to many problems pertaining to development contexts. India is an ideal setting to study our research question, having a longstanding social structure characterized by fragmentation along religious lines, as well as a rigid caste system. Issues such as social exclusion and public good provision (or lack thereof) along religious lines are widely documented (de Hann, 1997; Sen 2000; Bardhan et al., 2010; Das et al., 2011). ${ }^{1}$ We build upon existing household survey work on religious-based social exclusion in villages in West Bengal, India, and we focus our attention to the problem of religious discrimination among Muslim and Hindu communities in West Bengal.

When reviewing the literature on the effects of ethnic diversity on economic outcomes, Alesina and La Ferrara (2005) identify social identity theory as a means to provide micro-foundations for theoretical explanations as to why fragmentation affects economic performance. Social identity theory argues individuals attach utility to group membership and to the wellbeing of fellow group members to the detriment of outsiders — see Akerlof and Kranton (2000) and Basu (2007) for theoretical analyses of how social identity can affect

\footnotetext{
${ }^{1}$ This problem even extends to the breakdown of trade across different social groups (Anderson, 2011).
} 
economic decisions. This paper presents data from an artefactual field experiment examining how social fragmentation can impact cooperation through social identity.

Social identity theory argues that membership of a social group means individuals display a higher concern for the welfare of fellow 'in-group' members than outsiders (Tajfel et al., 1971). Experimental evidence from the lab and field supports this inter-group discrimination hypothesis in dictator games (Bernhard et al., 2006; Chen and Li, 2009), distribution games (Klor and Shayo, 2010), and prisoners' dilemma games (Goette et al., 2006; Charness et al., 2007), using both artificial and real social groups. Therefore, individuals should be more likely to cooperate with in-group members, even if doing so incurs them an economic cost, and particularly so if total welfare within the group increases as a result. Conversely, individuals may be less likely to cooperate with outsiders. The net effect is therefore a decline in cooperation as the number of outsiders increases (Smith, 2011).

Alternatively, individuals may only be willing to cooperate on a common enterprise if they believe others are likely to do so as well. In that sense, cooperation can take the guise of a coordination problem. The absence of formal institutions that facilitate coordination could lead to economies not achieving desirable equilibria (see Cooper, 1999 for a review of theory and experimental evidence on coordination games with applications to macroeconomics). While coordination problems are a feature of any economy, they are a crucial issue in many developing countries. In these economies, either property rights are not institutionally assured, or access to legal recourse in case of a dispute may be limited and/or costly (see Posner, 1998 and references therein). In this context, the belief by an economic agent about her counterpart's willingness to abide by an informal agreement is essential for economic activity to take place. In this context, a sense of group identity could help cooperation to the extent that individuals believe fellow in-group members are more likely to cooperate than outsiders (Brewer, 1986; Yamagishi and Kiyonari, 2000). Social psychological evidence suggests these expectations are stronger within group boundaries than across group divides (Tanis and Postmes, 2005; Yamagishi, Jin and Kiyonari, 1999).

To study the effect of social fragmentation on cooperation, we consider two classic cooperation games. The first is the prisoners' dilemma, in which cooperation is a strictly dominated strategy for individuals who care only about their own monetary payoff. Either 
player can unilaterally increase total welfare (at a personal cost) by cooperating. Experimental economists and social psychologists have looked at cooperation in the prisoners' dilemma as a measure of other-regarding preferences: if players care sufficiently for the welfare of their counterpart (or about the sum of payoffs), then it can be a dominant strategy to cooperate. However, if both players display other-regarding preferences, then the prisoners' dilemma in money payoffs can turn into a coordination game in utility payoffs. In that case, the outcome in which both players cooperate is still an equilibrium, but only if both players believe their counterpart will cooperate. ${ }^{2}$

The second game is the stag hunt game, in which two players must decide whether or not to cooperate. While defecting ensures a positive payoff, cooperating only pays off if the other player cooperates as well; otherwise the payoff from cooperation is zero. This means both players cooperating can also be an equilibrium of the game, provided players assign high enough probability to their counterpart doing so. Importantly, and unlike the prisoners' dilemma, a player's own other-regarding preferences play no role in determining behavior in this game, but beliefs about the other player's action do.

We study the effect of religious identity among Hindu and Muslim groups by varying the way our subjects are matched with each other. We implement in-group/in-group treatments where Muslim subjects play with fellow Muslim subjects and Hindu subjects play with fellow Hindu subjects; we also implement in-group/out-group treatments where Hindu subjects play with Muslim subjects. Finally, we have a control treatment where the identity of a subject's match is uncertain. To study the effect of fragmentation, we resort to a quasi-experimental approach. We take religious composition of villages as fixed, based on the village-level survey on religious fragmentation by Das et al. (2011). We select villages in two districts in West Bengal which conform to one of three categories: Muslim-dominated, where

\footnotetext{
${ }^{2}$ To see this, consider the version of the Prisoners' Dilemma we propose in Table 1, and consider a utility function of the form proposed by Charness and Rabin (2002): $U_{i}=\pi_{i}+\rho_{i}\left(\pi_{i}-\pi_{j}\right) r+\sigma_{i}\left(\pi_{j}-\pi_{i}\right) s$, where $r=1$ if $\pi_{i}>\pi_{j}$ and 0 otherwise; $s=1$ if $\pi_{j}>\pi_{i}$ and 0 otherwise and both $\rho_{i}$ and $\sigma_{i}$ are known. If $\rho_{i}<-1 / 4$ and $\sigma_{i}<1 / 4$, it is a dominant strategy to cooperate; if $\rho_{i}>-1 / 4$ and $\sigma_{i}<1 / 4$, the prisoners' dilemma in money payoffs turns into a coordination game in utility payoffs. See also Fehr and Schmidt (1999) who show that the linear public goods game, of which the prisoners' dilemma is a special case, can have multiple equilibria if players exhibit other-regarding preferences.
} 
over $90 \%$ of the population is Muslim; Hindu-dominated, where over $90 \%$ of the population is Hindu; and fragmented, where the Muslim and Hindu communities are roughly equal. ${ }^{3}$ Our experimental design combines identity treatments with village types to understand how social identity interacts with fragmentation.

We find evidence of in-group favoritism in fragmented villages in the prisoners' dilemma, in that cooperation rates are higher in in-group matches than in both unknown and outgroup matches. We find a very similar pattern of results in the stag hunt game, although it is of a smaller magnitude and it is not statistically significant. We find no evidence of out-group prejudice (defined as lower cooperation with an out-group member than with an unknown individual) in both the prisoners' dilemma and stag hunt games. In both games, cooperation rates among individuals of the same religion are lower in homogeneous villages than fragmented villages, even when controlling for village characteristics such as size, unemployment and literacy rates, which could be be proxies for social norms that can predict cooperation. Furthermore, we find cooperation rates amongst individuals of the same religion in homogeneous villages are no different to cooperation rates between two individuals of different religions in fragmented villages.

The rest of the paper is organized as follows. Section 2 gives a brief background to Hindu-Muslim relations which motivate our study. Section 3 describes the experimental design and procedures, Section 4 outlines the results and Section 6 discusses the results and concludes the paper.

\section{Background to Hindu-Muslim Relations in India}

Studying social identity is complex, especially given the difficulty in isolating the different identities which play a role in social and economic contexts. A key social institution which forges an individual's identity in India is religion. Recent Indian history has witnessed several episodes which have stoked traditionally tense relations between Hindus and Muslims. The

\footnotetext{
${ }^{3}$ Although the Indian census collects village-level data on religious composition, that information is classified and not available to researchers. We use data from Das et al.'s 2011 household survey in West Bengal on religious discrimination to select villages.
} 
partition on Bengal along Hindu-Muslim lines in 1905 and the second partition of Bengal into West Bengal and East Pakistan (now Bangladesh) in 1947, when the modern Indian state was formed are particularly relevant to our study. In both cases, the mass displacements of people led to numerous episodes of inter-religious violence (Akbar, 2003; Brass, 2003). Turner and Brown (1978) suggest that the relationship between Hindus and Muslims is insecure because post-partition India is demographically Hindu-dominant; there has been also a reversal of roles in the political sphere, as Muslims provided most of the ruling elite a couple of centuries earlier. The underlying division between the two religious groups have often manifested itself in conflict and violence in regular intervals between 1950 and 2000 (Mitra and Ray, 2013). Such regular conflicts suggest that the religious differences are socially entrenched in India. Recently, religious riots have been recorded in 2002 in the state of Gujarat, as well as in 2010 in West Bengal, the state in which we conduct our study. ${ }^{4}$

According to the Census of India 2001, 81\% of the total Indian population is Hindu and $13 \%$ is Muslim. In West Bengal, the state in which we conduct our study, five districts have a significant Muslim population, two of which are Murshidabad and Burdawan, where we carry out our experiments. In West Bengal, $65 \%$ of the rural population is Hindu and $33 \%$ is Muslim; in urban areas, the proportions are $85 \%$ and $13 \%$, respectively. The economic and social indicators are marginally worse for Muslims in India. In rural areas, there is a marginal difference in poverty ratios between Muslims and Hindus, but this difference is larger in urban areas (John and Mutaktar, 2005). ${ }^{5}$ 


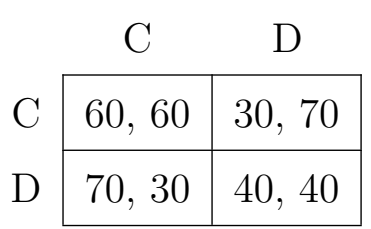

PD Game

\begin{tabular}{c|c|c|}
\multicolumn{1}{c}{$\mathrm{C}$} & \multicolumn{1}{c}{$\mathrm{D}$} \\
\cline { 2 - 3 } $\mathrm{C}$ & 80,80 & 0,40 \\
\cline { 2 - 3 } $\mathrm{D}$ & 40,0 & 40,40 \\
\cline { 2 - 3 } & &
\end{tabular}

SH Game

Table 1: Payoff matrices for the PD and SH games.

\section{Experimental Design, Procedures and Hypotheses}

\subsection{The Games}

We report data from two games, each of which captures important features of social behavior: the Prisoners' Dilemma (PD) game and the Stag Hunt (SH) game. We now briefly describe each game as it was implemented in our experiments, and our approach in analyzing and interpreting behavior in each of the games.

The PD game is the quintessential social dilemma, in which private incentives run against the welfare of the group. It is one of the most widely studied games by scholars investigating the determinants of cooperation. While it is a dominant strategy to defect, both players achieve the joint payoff-maximizing outcome if they cooperate. The left payoff matrix in Table 1 reproduces the formulation of the PD game used in our experiment, where payoffs are denoted in Indian rupees (INR). There are two available strategies, C and D, which we will denote henceforth as 'cooperate' and 'defect'. ${ }^{6}$

The experimental economics literature on the PD game reports a non-trivial share of observations recording the (dominated) strategy of cooperation in one-shot or finitely repeated interactions (Dawes, 1980; Roth, 1988; Sally, 1995). Cooperation in one-shot or

\footnotetext{
${ }^{4}$ See New York Times, 2014 and Times of India, 2010, respectively.

${ }^{5}$ The marginal per capita expenditure index for Muslims (Hindu $\left.=100\right)$ for across India is 96.3 and West Bengal is $87 \%$ (Rural) and $91 \%$ (Urban). According to the head count data on poverty (Census of India, 2001) in rural West Bengal 37\% of Muslims and 29\% of Hindus are counted as poor (West Bengal 32\% are poor, while the India head count is $27 \%$ ). The Hindu-Muslim literacy gap in rural West Bengal is $11 \%$ (Hindus $67 \%$ and Muslims 55.6\%) and in urban West Bengal it is $18 \%$ (Hindus 84\%, and Muslims 66\%).

${ }^{6}$ This was not the nomenclature used in the experiment; we employ it in the paper for ease of exposition. See the Appendix for copies of the instructions and materials.
} 
finitely-repeated PD games has been attributed to other-regarding preferences, such as efficiency preferences (Reuben and Riedl, 2013; Capraro et al. 2014), or impure altruism (Andreoni, 1990). ${ }^{7}$ In our analysis of behavior in the PD game, we focus on the proportion of individuals who chose to cooperate, either due to preferences for surplus or due to beliefs about others' actions, and how that proportion changes as a function of village fragmentation, in-group/out-group matching and measures of social identity.

The SH game looks at a different aspect of cooperation: the role of beliefs. ${ }^{8}$ Unlike the PD game, cooperation among two self-interested players is a possible Nash equilibrium of the game. The payoff matrix on the right-hand side of Table 1 reproduces the SH game used in our experiment, where payoffs are in INR. If a player believes the probability his/her counterpart will cooperate is higher than $1 / 2$, then it is a best-reply to cooperate; if in contrast the player believes the probability of the counterpart cooperating is lower than $1 / 2$, then it is a best-reply to defect. These beliefs form the basis of two pure-strategy Nash equilibria: (C,C) and (D,D). A third mixed-strategy Nash equilibrium exists when both players believe the probability of cooperation is exactly $1 / 2 .^{9}$ The key aspect of this game is that the main determinant of players' optimal choice is their belief about their counterpart's action. Unlike the PD game, out-of-equilibrium behavior is not efficiencyincreasing: cooperating when the other player does not cannot benefit one's counterpart. Furthermore, both equilibria are the only outcomes which minimize income inequality. When

\footnotetext{
${ }^{7}$ Reuben and Riedl (2013) and Andreoni (1990) discuss the role of efficiency preferences and impure altruism in the linear public good game, which is an N-player, continuous version of the prisoners' dilemma if $b / N<c<b$, where $b$ is the marginal per capita return to the public good and $c$ is the cost of contribution. Kreps et al. (1992) show that cooperation can be attained by rational, self-interested players if there is incomplete information about player types. However, we can rule out such motivations in our case, since our experiment only entails one-shot interactions.

${ }^{8}$ The stag hunt game can also be interpreted as the long run payoffs of two players playing particular infinitely-repeated prisoners' dilemma games using grim trigger strategies (Skyrms, 2001). In the experimental implementation, because game payoffs are denoted in cash rather than utility, risk attitudes may matter, but it is unlikely that risk attitudes will systematically vary with village composition and/or social identity.

${ }^{9}$ Note that while our game retains the payoff structure which defines a stag hunt (i.e. $\pi_{i}(C, C)>$ $\left.\pi_{i}(D, C) \geq \pi_{i}(D, D)>\pi_{i}(C, D)\right)$, in our case $(\mathrm{C}, \mathrm{C})$ is the payoff-dominant equilibrium. There is no risk-dominant equilibrium as the product of deviation losses is the same for both pure strategy equilibria.
} 
analyzing behavior in the SH game, we focus on the fraction of individuals who choose to cooperate, taking it as a proxy for beliefs about the likelihood the other player will also cooperate, and how those beliefs change as a function of village fragmentation and in-group/out-group matching.

\subsection{Experimental Design}

To study the effect of religious fragmentation on behavior in our two games, and our participants from three different types of villages, based on their religious composition: "Homogeneous - Muslim" and "Homogenous - Hindu" villages, where 90\% or more of the village's population was of one religion, and "Fragmented" villages, where no more than $60 \%$ of the village's population was of one religion. Village-level data on religious composition is not publicly available data - the Indian Census data only provides religious composition data at the district level. To circumvent this problem, we selected our villages based on data from Das et al. (2011), who conducted a large-scale household survey on the effects of religious fragmentation in West Bengal villages. ${ }^{10}$

In order for this quasi-experimental design to be valid, we require village composition to be exogenous. If people self-select into different villages on the basis of their religious breakdown, we would not be able to identify the causal mechanism between fragmentation and behavior. We are confident that our assumption about the exogeneity of villages' religious composition holds. In India, rural-rural migration is predominantly due to marriage, whereby women move to their husband's village; other motives include family reasons, employment and education (Bhattacharya, 2000). All of these motives are uncorrelated with a village's religious composition. About $70 \%$ of our participants reported having been born in the village and/or their father and grandfather being born in the village. Another potential concern with using a quasi-experimental design is that the participant sample systematically

\footnotetext{
${ }^{10}$ The village selection was further restricted by whether or not a given village would have an appropriate building for the running of sessions - we opted for villages that had a primary school. The villages that fit our demographic criteria, had a primary school, and whose local authority would allow us to use it were the following: Alampur, Bhurkunda, Char Mathurapur, Chupi, Domohani, Ganfulia, Gokarno, Hasanpur, Jhikra, Kanakpara, Kirtipur, Pilsowa, Roshanpur, Shuhari, Sridharpur and Tungi.
} 


\begin{tabular}{|c|c|c|c|c|c|}
\hline & & \multicolumn{4}{|c|}{ Treatment } \\
\hline & & M-M & $\mathrm{H}-\mathrm{H}$ & $\mathrm{H}-\mathrm{M}$ & MIX \\
\hline \multirow{3}{*}{ 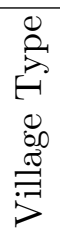 } & Homogenous - Muslim & $(94,3)$ & - & - & - \\
\hline & Fragmented & $(40,1)$ & $(70,2)$ & $(130,4)$ & $(58,2)$ \\
\hline & Homogenous - Hindu & - & $(124,4)$ & - & - \\
\hline
\end{tabular}

Note: (\# of subjects, \# of villages).

Table 2: Experimental design

differs on the basis of the type of village (i.e. homogeneous vs. fragmented) we sampled. We are confident that this is not the case on the basis of data on observable characteristics we collected from participants, including gender, age, caste, profession, marital status, place of birth, land ownership and literacy — see Table 4 in the appendix for details.

In the fragmented villages, we conducted four different types of treatments, each of which refers to a matching protocol. The M-M treatment consisted of sessions in which all participants were Muslim. Likewise, the H-H treatment was such that the only participants were Hindu. The H-M treatment consisted of sessions in which half of the participants were Hindu and the other half were Muslim, and participants knew they were playing someone from another religion. Finally, the MIX treatment consisted of sessions with both Hindu and Muslim participants, but where the religious identity of their match was uncertain. We elaborate on how we accomplished this when we describe the experimental procedures below. In the homogeneous villages we conducted only $\mathrm{H}-\mathrm{H}$ or $\mathrm{M}-\mathrm{M}$ sessions, the religious composition of these villages meant in most cases there were very few or no residents of the other religious group. Table 2 describes the experimental design.

\subsection{Participant Recruitment and Experimental Procedures}

We employed a mixed-gender, mixed-religion team of local research assistants to recruit participants and conduct the sessions, so as to minimize any possible experimenter demand effect. A week ahead of a planned session, our research assistants travelled to the village where that session would take place. A set of neighborhoods were randomly selected, and 
within each neighborhood, recruitment was done on a door-by-door basis. On a given street, every two consecutive houses were skipped and the third house would be approached and those who agreed to participate would be signed up. Participants were reminded about the session the day before it took place. Participants did not know the purpose of the experiment: when approached, they were informed that the research team would be conducting decisionmaking sessions. We conducted one session per village in the village's primary school. ${ }^{11}$

We made religious identity salient by making the names of participants common knowledge, and by allowing participants to visually identify their potential counterparts in the games participants played. ${ }^{12}$ Upon arrival, participants were asked to remain outside the main school building and wait for their name to be called out. Upon hearing their name, each participant was taken to the main classroom, and told to sit at one of the ends of the classroom, facing the middle. It is reasonably easy to identify someone as a function of their name, since Muslim names are quite different from Hindu names. Calling in participants individually made their religious identities salient (and established the existence of an outgroup) in an inconspicuous way. ${ }^{13}$

Participants were told they would be making a series of decisions with someone on the other side of the room, and they were told that they would always make each decision with a different person. This allowed participants to identify the religious identity of their potential counterparts, either through their choice of attire, or by recognizing participants across the

\footnotetext{
${ }^{11}$ After the first session in the first village, it was clear that participants discussed the experiments among their social network. Due to a combination of the novelty factor and the generous incentive payments, the sessions themselves raised interest among villagers in the hours after the sessions ended, therefore contaminating the pool of potential participants in that village.

${ }^{12}$ This is a combination of two existing methods of making identity salient: Habyarimana et al. (2007) induce ethnic identity in experiments conducted in Uganda using photographs of participants, while Fershtman and Gneezy (2001) induce ethnic identity in experiments conducted in Israel using participants' names.

${ }^{13}$ Eliciting religious identity through names could have also elicited participants' caste identity as well. We control for this possibility in the econometric analysis of the data, and our results are robust.
} 
room. ${ }^{14}$ However, since there were typically 15 to 20 participants on either side of the room, it was impossible for participants to know who their counterpart was in each game, therefore preserving the anonymity of decisions. This was important since $83 \%$ of participants stated in the post-experimental questionnaire that they knew or recognized most of the participants in the room.

In the $\mathrm{H}-\mathrm{H}$ and $\mathrm{M}-\mathrm{M}$ sessions, all subjects in the room shared the same religion, so the seating arrangement was irrelevant. In the H-M sessions, Hindu subjects were all seated in one end of the room, while Muslim subjects sat in the other end; finally, in the MIX sessions, Hindu and Muslim subjects sat on both ends of the room.

Sessions were split in three parts. In the first part, participants played three games: the Prisoners' Dilemma, the Stag-Hunt game and the Tullock contest (in that specific order). In the second part of the session, participants played a series of individual decision-making tasks. ${ }^{15}$ In the third part, participants individually responded to a survey in a separate room, got feedback on the decisions made in the experiment, and received their corresponding payment. An experimenter standing in the middle of the room read the instructions aloud, using visual aids to explain the incentive structure of each game (see Appendix for the experimental materials). We did not employ written instructions since about a third of our subjects was unable to read or write. As such, we denoted payoffs in INR and used images of Indian notes and coins to represent payoffs.

A potential pitfall of running experiments in which subjects do multiple tasks is that there may be contamination of behavior across games, such as order effects, wealth effects, behavioral spillovers or hedging. Order effects are certainly possible in our experiment; while they would affect cooperation levels, the hypotheses of interest are on differences in behavior across villages and/or treatments, all of which were exposed to the same order of play. We minimized the scope for wealth, spillover and hedging effects in our experiment by (a) not informing subjects of the games they were about to play ahead of time; (b) not providing

\footnotetext{
${ }^{14}$ The experiments were unusual events in the villages, and many participants came to the sessions in formal attire. In rural Bengal, Hindu men wear "dhoti," a long white cloth draped around the waist, and Muslim men wear "lungi," a piece of checkered cloth also worn around the waist. Hindu women wear "saris," as well as "bindi" on their forehead, while Muslim women wear "salwar" and "kamiz" and no "bindi."

${ }^{15}$ The data from the Tullock contest, as well as the individual tasks is the focus of companion papers.
} 
feedback between games; (c) implementing a turnpike matching scheme, whereby subject $i$ was never matched with the same person twice, and any of $i$ 's matches would never play each other. Subjects were reminded of these features at the start of each game. To check that subjects may have hedged their decisions in the two games, we computed the Fisher's exact test which did not reject the null hypothesis of independence of behavior in the two games $(p=0.186) .{ }^{16}$

The first part of the session took approximately 60 minutes and sessions as a whole lasted on average 3 hours. Average payment for the PD game was INR 53.26 (\$0.86), average payment for the SH game was INR 43.17 (\$0.70) and average payment for the whole session was INR $598.70(\$ 9.65) \cdot{ }^{17}$

\subsection{Hypotheses}

We are primarily interested in studying how fragmentation along religious lines affects cooperation. Even though the Prisoners' Dilemma and Stag Hunt games propose a different strategic environments, our hypotheses are applicable to both games; we therefore only outline one set of hypotheses for ease of exposition. First, we fix village-level religious fragmentation, and we examine in-group/out-group differences in behavior. Second, we restrict interactions to be only among in-group members and we study the effect of village-level fragmentation and the salience of religious identity by comparing fragmented villages to homogenous ones. We will state our alternative hypotheses, given that our general null hypothesis is that behavior will not differ either by treatment or by village type.

Our first hypothesis follows from a well-established literature in social psychology and experimental behavioral economics, which establishes that individuals display favoritism towards members of their social group relative to an out-group (Tajfel et al., 1971). We

\footnotetext{
${ }^{16}$ We found similar results when analyzing the Muslim and Hindu sub-samples. In the Muslim (Hindu) sample, the Fisher's exact test on the null of independence in behavior between in the PD and SH games yielded a p-value of 0.391 (0.379).

${ }^{17}$ The average daily wage for a rural worker in West Bengal in 2011 ranged from INR 105 (\$1.74) for an unskilled female worker to INR 297.50 (\$4.93) for a male well digger; in most agricultural occupations average daily wages were approximately INR 130 (\$2.15), Government of India (2012).
} 
compare treatments where the likelihood of cooperating with an in-group is $100 \%$ (H-H/MM) to the case where that likelihood is $50 \%$ (MIX) or $0 \%$ (H-M).

Hypothesis 1a: In fragmented villages, there will be higher frequencies of cooperation in $H-H / M-M$ than in $M I X$.

Hypothesis 1b: In fragmented villages, there will be higher frequencies of cooperation in $H-H / M-M$ than in $H-M$.

The existence of in-group biases does not necessarily mean that there will be negative out-group biases, either theoretically (Allport, 1954; Brewer, 1999), or empirically (Morita and Servátka, 2013). In our experiment, the relevant treatments to establish this comparison are the H-M treatment, where the likelihood of playing with an out-group member is $100 \%$ and the MIX treatments where that likelihood is $50 \%$. On that basis, we state our next hypothesis.

Hypothesis 2: In fragmented villages, there will be higher frequencies of cooperation in MIX than in $H-M$.

We now turn to the test of whether or not social identity can account for the effect of fragmentation. Brewer (1991) theorizes that in-group identification is a function of two competing needs. On the one hand, individuals have a need for inclusion: an isolated individual would seek to identify herself with a collective. On the other hand, people require a degree of distinctiveness: members of very large groups may search for alternative identities through which they can affirm their uniqueness. It follows that subjects' sense of religious identity should be less salient in villages where their own religion dominates: individuals ought to identify with groups which provide them with a better sense of uniqueness. In contrast, the salience of religious identity should be strongest in fragmented villages, since not only there is an out-group to provide a comparison, but also because both religious groups are equally numerous within the village. Existing lab evidence supports this argument: Eckel and Grossman (2005) show in a laboratory setting that inducing group identity is only effective if that identity is sufficiently salient. Therefore, we should find higher cooperation 
levels in fragmented villages than in homogeneous villages. ${ }^{18}$ This is our third and final hypothesis.

Hypothesis 3: There will be higher frequencies of cooperation in fragmented villages than in homogeneous villages in both $H-H$ and $M-M$ treatments.

\section{Results}

We start by examining behavior in the PD game, followed by the analysis of the data from the SH game. We complete the analysis by combining our behavioral data with postexperimental survey data which includes measures of attitudes towards out-group members and socio-economic characteristics at both individual and village level. In our analysis, we use each individual's decision as an independent observation. We first test for treatment effects using standard statistical techniques and we report two-sided tests throughout; we then check for the robustness of our results using regressions with clustered standard errors at the session level to control for possible within-session correlation in decisions.

\subsection{The PD Game}

Figure 1 displays the fraction of cooperation decisions in the PD game in fragmented villages as a function of the identity of the decision-maker's counterpart. In order to make the appropriate comparisons, we divide the H-M treatment data into H-M - Muslim, corresponding to the Muslim participants' decisions, and H-M - Hindu, referring to the Hindu participants' decisions (likewise for MIX).

We start by examining the existence of in-group biases. As predicted, the average cooperation rates are higher when subjects play an in-group member than when they play an out-group member. Cooperation rates by Muslim subjects are 34 percentage points higher when playing an in-group member (M-M, 0.95) than when playing an out-group member $(\mathrm{H}-\mathrm{M}, 0.64, p=0.001$, Fisher's exact test - henceforth FET); cooperation rates by Hindu

\footnotetext{
${ }^{18}$ Naturally, cooperation rates could be driven by factors other than social identity salience. We will control for village-specific effects in our econometric analysis to separate the effect of identity on cooperation.
} 
subjects are higher in $\mathrm{H}-\mathrm{H}(0.80)$ than $\mathrm{H}-\mathrm{M}(0.66)$ by 14 percentage points $(p=0.023, \mathrm{FET})$. Average cooperation in the in-group/in-group matches (H-H or M-M) is also higher than that

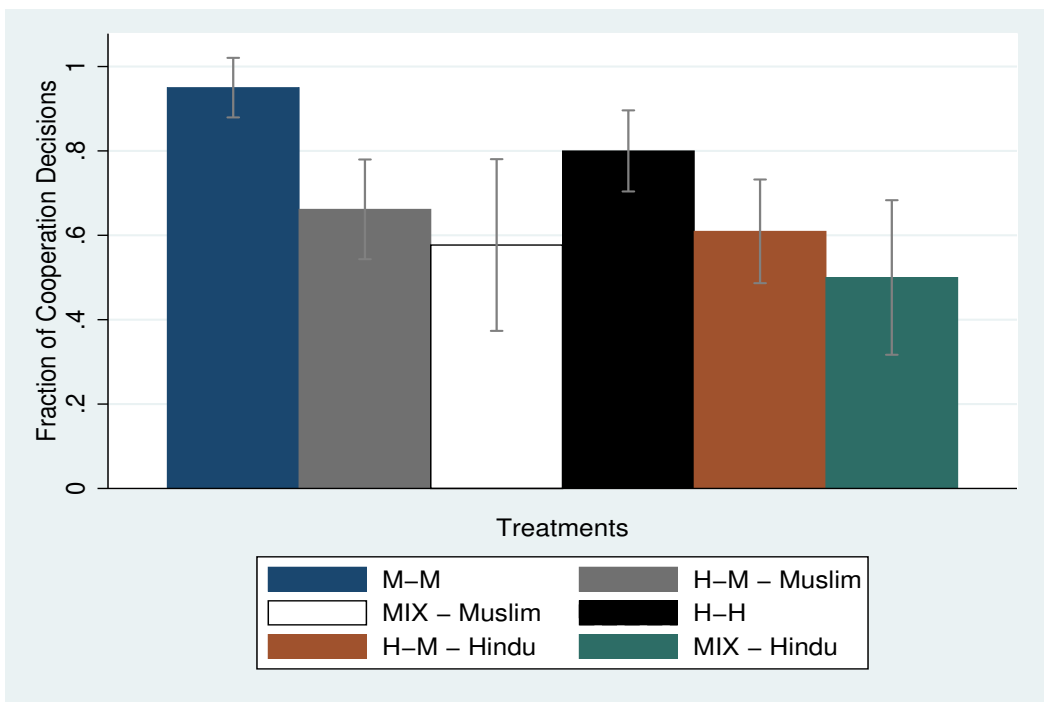

Figure 1: Fraction of cooperation decisions in the PD game - fragmented villages.

in the case where the identity of the counterpart is uncertain (MIX). The cooperation rate among Muslim participants is 37 percentage points lower in MIX than in M-M $(p<0.001$, FET), while among Hindu participants the cooperation rate is 30 percentage points lower in MIX than in $\mathrm{H}-\mathrm{H}(p=0.004, \mathrm{FET})$.

We now compare cooperation rates between the H-M and MIX treatment. While the rates of cooperation are nominally higher in H-M than MIX for both religious groups, in neither case are these differences statistically significant (Muslim: $p=0.477$; Hindu: $p=0.383, \mathrm{FET})$.

Observation 1: Cooperation rates in the PD game are higher when Hindu or Muslim participants play with an in-group member than when they play with an out-group member or with an unknown group member.

Observation 2: The cooperation rates when Hindus or Muslims play an unknown group member are no different to the case when they play an out-group member.

We now turn to the effect of village-level fragmentation on behavior when subjects are matched with in-group members. Figure 2 displays the fraction of cooperation decisions in 


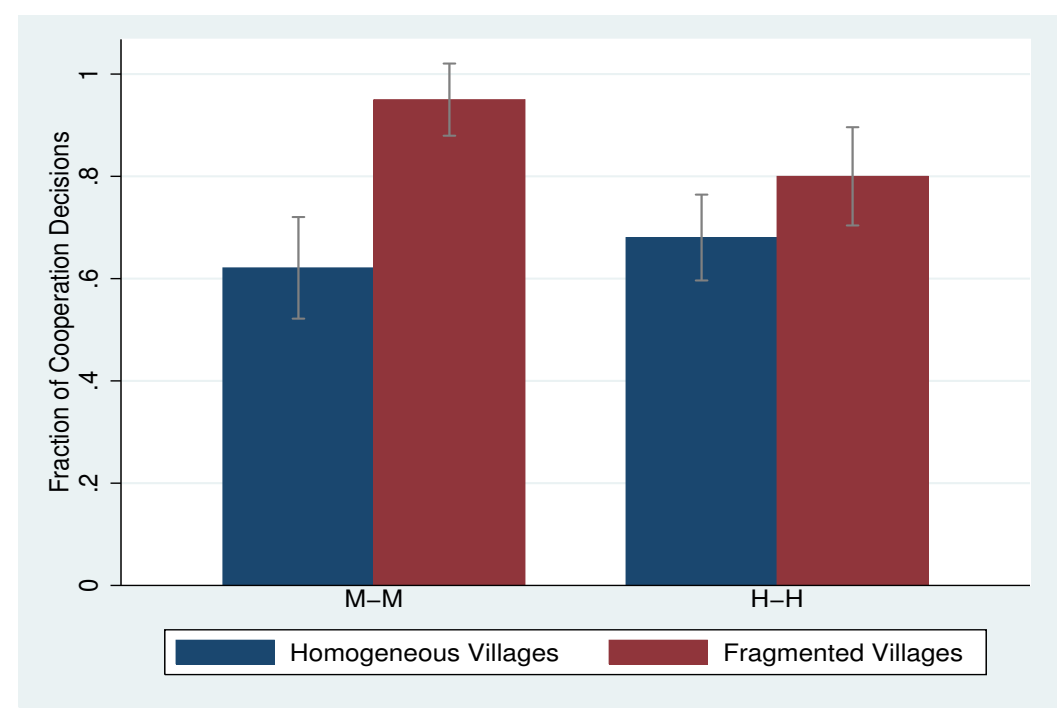

Figure 2: Fraction of cooperation decisions in the PD game - homogeneous vs. fragmented villages.

the PD game among in-group/in-group matches, comparing fragmented villages to homogeneous villages. ${ }^{19}$ Among Muslim subjects, there is a significantly higher rate of cooperation in fragmented villages (0.95) than in homogeneous villages $(0.62, p<0.001, \mathrm{FET})$. Among Hindu subjects, there is a smaller difference in cooperation rates between fragmented $(0.80)$ and homogeneous (0.66) villages, which is only marginally significant ( $p=0.099$, FET).

Ultimately, what is the effect of fragmentation? On the one hand, fragmentation could enhance in-group favoritism, albeit at the possible expense of cooperation with outgroup. To determine which effect dominates, we compare behavior in $\mathrm{H}-\mathrm{M}$ in fragmented villages to $\mathrm{H}-\mathrm{H} / \mathrm{M}-\mathrm{M}$ data in homogeneous villages. In the case of Hindu subjects, recall that the fraction of cooperation choices was equal to 0.61 in $\mathrm{H}-\mathrm{M}$, and equal to 0.68 in $\mathrm{H}-\mathrm{H}$ in homogeneous villages $(p=0.336, \mathrm{FET})$. In the case of Muslim subjects, the fraction of cooperation choices was equal to 0.66 in $\mathrm{H}-\mathrm{M}$, and equal to 0.62 in $\mathrm{M}-\mathrm{M}$ in homogeneous villages $(p=0.620, \mathrm{FET})$.

Observation 3: Cooperation rates in the PD game among in-group members are higher in fragmented villages than homogeneous villages, both among Muslim and Hindu partici-

\footnotetext{
${ }^{19}$ Recall that we could not collect data on H-M or MIX treatments in homogeneous villages, since there were very few or no members of the minority group in those villages.
} 
pants. Cooperation rates with in-group members in homogeneous villages are not different to cooperation rates with out-group members in fragmented villages.

We conclude our analysis of the PD game by briefly examining differences in cooperation levels across religious groups. In fragmented villages, we observe higher cooperation rates among Muslims than Hindus when they are playing an in-group subject $(p=0.047$, Fisher's exact test), but we observe no differences in cooperation rates between the two religious group in either the H-M $(p=0.586$, FET) or MIX $(p=0.605$, FET $)$ treatments. We see no difference in cooperation rates among Muslims or Hindus from homogeneous villages when they play a fellow in-group member $(0.68=0.62, p=0.390, \mathrm{FET})$. In fragmented villages (see Figure 1) we also do not observe any differences in the fraction of cooperation across religious lines when subjects play an out-group member $(0.66=0.61, p=0.586$, FET), or when they play an unknown group member $(0.58=0.50, p=0.605, \mathrm{FET})$. The only differences in behavior across the two religious types are restricted to in-group/in-group matches in fragmented villages $(0.95=0.80, p=0.047, \mathrm{FET})$. This suggests Muslims exhibit higher in-group favoritism than Hindus. This is noteworthy, as Muslims are a sizable minority in the state of West Bengal.

Observation 4: Cooperation rates in the PD game among in-group members are higher among the Muslim subjects than Hindu subjects in fragmented villages only.

\subsection{The SH Game}

We now repeat the above analysis for the SH game. Figure 3 displays the fraction of cooperation decisions in the $\mathrm{SH}$ game in fragmented villages as a function of the identity of the counterpart, conditional on the religious identity of the decision-maker. The qualitative pattern is similar to that of the PD game in that, conditional on the religious identity of the decision-maker, cooperation decisions are nominally higher in in-group/in-group matches. However, we do not find a significant difference between H-M and either M-M $(p=0.223$, FET) or H-H $(p=0.296$, FET $)$. We do observe a statistically higher cooperation rate between H-H and MIX ( $p=0.018$, FET), but not when we compare M-M to MIX $(p=0.132$, 


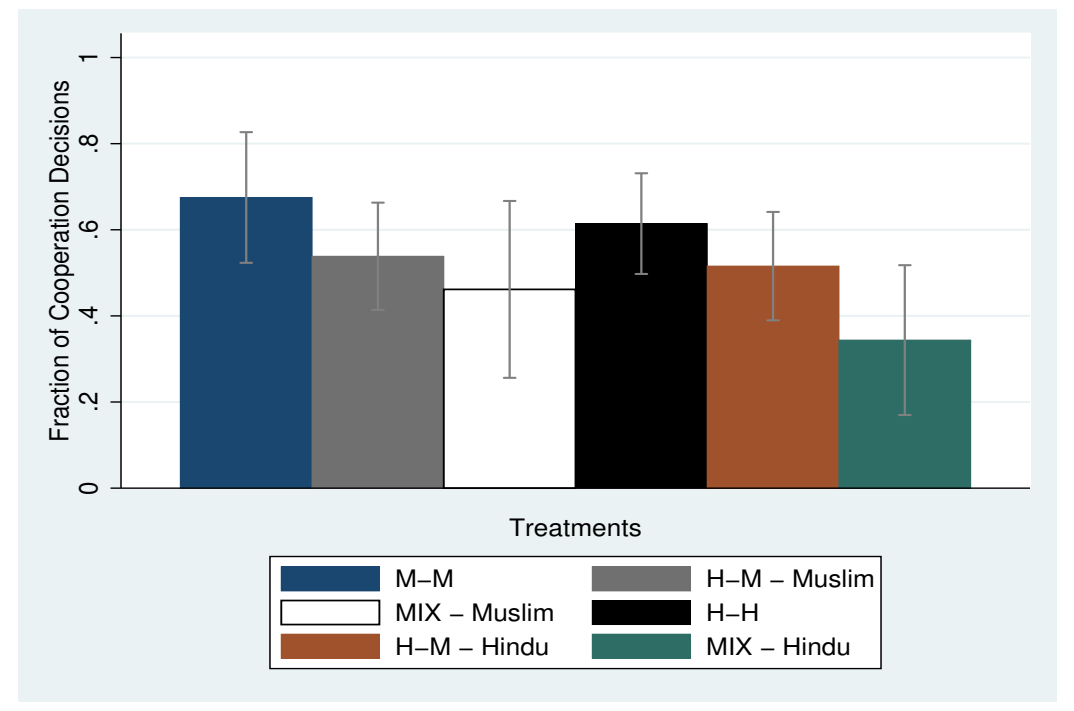

Figure 3: Fraction of cooperation decisions in the SH game - fragmented villages.

FET). We also do not find any significant difference between H-M and MIX for either the Muslim sample $(p=0.645, \mathrm{FET})$ or the Hindu sample $(p=0.132, \mathrm{FET})$.

One could argue that the lack of significance is due to the small sample size, since we are breaking up the data along religious groups. To check for this, we pool Muslim and Hindu samples and compare the cooperation rates in the pooled $\mathrm{H}-\mathrm{H}$ and $\mathrm{M}-\mathrm{M}$ sessions to the pooled H-M sessions. We do not find a significant difference ( $p=0.115$, FET). However, when comparing pooled H-H and M-M sessions to pooled MIX sessions, we do find a significant difference $(p=0.003, \mathrm{FET})$. This leads to our next observation.

Observation 5: Cooperation rates in the SH game are higher among Hindus when they play with an in-group member than when they play with a player whose identity is uncertain. That difference is not statistically significant in the Muslim sample.

We now turn to the effect of village fragmentation on behavior in the SH game, conditional on subjects playing with an in-group member. Figure 4 shows the fraction of cooperation decisions in $\mathrm{M}-\mathrm{M}$ and $\mathrm{H}-\mathrm{H}$, conditional on village type. Like in the PD game, we observe significantly higher cooperation rates in fragmented villages than in homogeneous ones. In the Muslim sample, cooperation is 20 percentage points higher in fragmented villages $(p=0.040, \mathrm{FET})$, while in the Hindu sample that difference is equal to 14 percentage points 


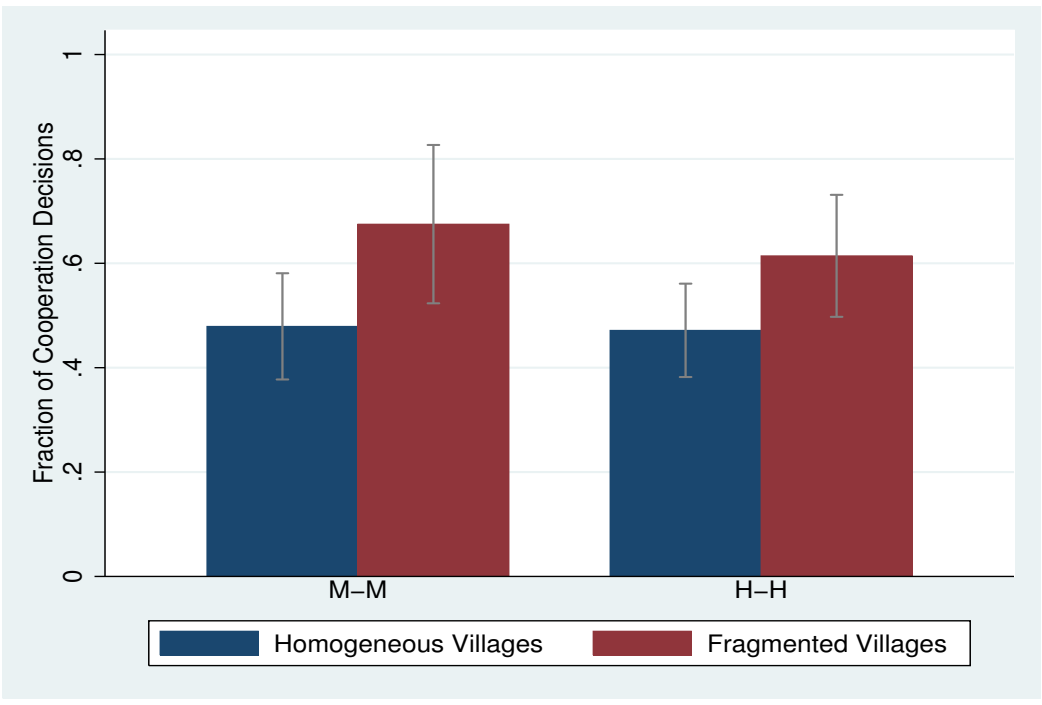

Figure 4: Fraction of cooperation decisions in the SH game - homogeneous vs. fragmented villages.

$(p=0.072, \mathrm{FET})$.

Are frequencies of cooperation in the $\mathrm{SH}$ game higher in when subjects play an ingroup member in homogeneous villages than when they play an out-group member in fragmented villages? The answer is, like the PD game, no: the frequency of cooperation by Muslim subjects when playing an in-group match in a homogeneous village is 0.48 , while the frequency of cooperation by Muslim subjects when playing with a Hindu counterpart in a fragmented village is $0.53(p=0.522, \mathrm{FET})$. Likewise, the cooperation frequency by Hindu subjects when playing the $\mathrm{SH}$ game in homogeneous villages is 0.47 , while their cooperation frequency when playing Muslim subjects in fragmented villages is $0.52(p=0.644, \mathrm{FET})$. In short, fragmented villages have higher cooperation rates when players belong to the same religious group, and no worse cooperation rates when players are from different groups.

Observation 6: Cooperation rates with in-group members in the SH game are higher in fragmented villages than in homogeneous villages, for both religious groups. Cooperation rates within religious groups in homogeneous villages are no different to cooperation rates across religious groups in fragmented villages.

We conclude this part of the analysis by looking at differences in behavior across 
religious groups. There are no significant differences in cooperation levels between Muslim and Hindu subjects in any condition. ${ }^{20}$

Observation 7: Conditional on village type and treatment, there are no differences in cooperation rates in the SH game between Muslim and Hindu participants.

\subsection{Individual Heterogeneity and Strength of Affiliation}

We now extend our analysis of behavior by introducing individual-level and village-level heterogeneity as potential drivers of behavior, using data from our post-experimental survey. In addition to socio-demographic information, we also collected several measures which proxy a sense of affiliation to different social groups. These included national-level identity, village-level identity, and religious identity. We also collected a number of measures of individual attitudes towards out-group members, where out-groups are defined along caste or religious lines. These included questions on attitudes towards inter-religious marriage, or how participants would feel if their neighbor would profess another religion or is of a different caste. $^{21}$ We also measured attitudes towards religious integration in school, and perceptions of religious diversity in their village. For details on the questionnaire, please see the Appendix.

Interestingly, our measures of in-group affiliation were remarkably consistent across our sample: over $90 \%$ of participants identified themselves along national and religious lines, and less than $5 \%$ identified themselves with their village (despite almost $70 \%$ of our participants stating being born in their village). Ideally, we would have wanted to have two distinct measures of affiliation, one regarding the in-group, and the other regarding the out-group, since the existence of an in-group bias does not mean there should be a negative out-group bias (Brewer, 1991). The lack of variation in the responses to our religious in-group attitude question does not allow us to measure econometrically the effect of in-group attitudes on behavior, so we are left with measures of out-group bias. We did, however, get some variation on our measures of out-group attitudes, which allows us to analyze how they correlate

\footnotetext{
${ }^{20}$ Fragmented villages, H-M - Muslim = H-M - Hindu: $p=0.861 ; \mathrm{H}-\mathrm{H}=\mathrm{M}-\mathrm{M}: p=0.545 ;$ MIX - Muslim $=$ MIX - Hindu: $p=0.425$. Homogeneous villages, $\mathrm{H}-\mathrm{H}=\mathrm{M}-\mathrm{M}: p=1.000$, all comparisons, FET.

${ }^{21}$ Muslims and Hindus typically reside in different areas of a given village, as do Hindus of different castes.
} 
with behavior when subjects are matched with an out-group player. We estimated the Logit model outlined in equation (1):

$$
\operatorname{Pr}\left(C_{i}^{g}=1 \mid X\right)=\exp (\beta X) /[1+\exp (\beta X)]
$$

where our dependent variable, $C_{i}^{g}$, is the decision by player $i$ to cooperate in game $g$. In the $\mathrm{PD}$ and $\mathrm{SH}$ game, this variable equals one if participant $i$ chose $\mathrm{C}$ and zero otherwise, while $\mathrm{X}$ is the vector of independent variables and $\beta$ is a vector of parameters to be estimated.

We consider two specifications of this model. The restricted version of our econometric model replicates the analysis done so far, and $X$ only includes treatment dummies $M-M, H$ $H$ and $H-M$ ( $M I X$ is the omitted category), plus the variable Muslim, which equals one if subject $i$ is Muslim, and its interaction with $H-M$.

In the unrestricted version of our econometric model, $X$ also encompasses a number of different variables from our post-experimental survey, which we now describe. Our first variable, $\operatorname{DisOG}_{i}$ measures attitudes towards those of a different religion; it equals one if participant $i$ stated disliking members of another religion (either Hindu or Muslim) and 0 otherwise. We interact it with the $H$ - $M$ treatment dummy to measure the effect of out-group attitudes on behavior towards the out-group.

Subjects also reported if they belonged to one of the following categories: SC (Scheduled Classes, sometime denoted in contemporary literature as 'Dalits'), ST (Scheduled Tribes) and OBC (Other Backward Classes). These social groups encompass historically disadvantaged people, who have recognition in the Indian Constitution and benefit from widespread affirmative action policies and assured political representation. These groups, particularly OBCs, exist across religious lines (Sachar Committee Report, 2006). ${ }^{22}$ Based

\footnotetext{
${ }^{22}$ The India Census has collected data on OBCs among Muslim in response to the Mandal Commission Report in 1980 that recommended the inclusion of scheduled classes (SCs) and other backward classes (OBCs) from the Muslim communities in Government of India's affirmative action programs. The 1901 Census of India classified the Muslims in India in three categories: the Ashrafs, Muslims who could trace their lineage to foreign countries and converts from higher Hindu castes; the Ajlafs, Muslims who were converts from lower castes but whose occupation was considered to be "clean"; and Arzal, who had converted from the lowest ranks of the caste hierarchy. Broadly, the Ajlafs get categorized as OBCs and the Arzal get categorized as SCs. OBC- and SC-Muslims are eligible for the affirmative actions of the State and Central Governments.
} 
on this information, we constructed the variable PropMyCaste $e_{i}$, which is the proportion of subjects on the other side of the room that share the same caste group as subject $i$. When constructing this variable, we restricted ourselves to the side of the room opposite the decision-maker, since this is the set of possible matches for a given subject. We interacted PropMyCaste $_{i}$ with a dummy, Adv, which equals one if a subject does not belong to SC, ST, or OBC. This part of the analysis serves as a robustness check on the existence of in-group biases along dimensions other than religion; here we exploit uncontrolled caste heterogeneity within sessions. Subjects in our experiment would have been able to identify the "social class' of their counterparts in the room by their name (announced outside the room) and potentially by their physical appearance. We also control for the possibility that subjects may know each other and therefore may cooperate with each other, irrespective of the treatment, with a view to extract maximum earnings from the experimenter. We inquired in our post-experimental survey about how many people a subject knew in the room. Most subjects stated recognizing or knowing most other participants. We generated the dummy variable $K$ nowAll, , which equals 1 if subject $i$ stated knowing all or almost all other subjects in the room.

We also include variables that capture village-level heterogeneity. These variables are intended to proxy other social norms that may also explain differences in cooperation levels across different types of villages. The variable DistanceHC measures the distance to the village's nearest health center; it is a proxy of how isolated the village is. We conjecture that people who live in isolated communities rely more on informal social networks for risk sharing, and therefore, the effect of identity should be stronger in such communities. Using data from the 2011 India Census, we construct the variable VillPop which is the village's population. We control for village size in our econometric estimation, as religiously-homogeneous villages in India tend to be smaller than heterogeneous ones. This means village size could potentially be driving our result on the effect of fragmentation. Two effects could be at play. On the one hand, cooperation levels should be lower in larger villages; on the other hand, larger villages could conceivably develop norms of inter-religious tolerance and acceptance due to higher economic activity, thus potentially leading to more cooperation. ${ }^{23}$ We also take 2011 India

\footnotetext{
${ }^{23}$ See Isaac et al. (1994) and Weber (2001) for evidence of group size on cooperation in public good games
} 
Census data on village illiteracy rates (Vill Ilit) and village unemployment rate (VillUnemp). These variables should capture the economic circumstances of villages, particularly wealth. It is plausible to presume that the financial stakes are higher in poorer villages; it is also possible that subjects in economically depressed villages are less likely to cooperate, since public good provision in those villages may be lower. Finally, Male $e_{i}$ is a gender dummy and $A g e_{i}$ is the reported age of subject $i$.

Regression (1) replicates our analysis of behavior in the PD game, and broadly confirms our findings. Cooperation rates are significantly higher in $M-M$ and $H-H$ than both our control condition, $\operatorname{MIX}(M-M: z=12.74, p<0.001 ; H-H: z=3.67, p<0.001)$ and $H-M(M-$ $M=H-M+H-M \times$ Muslim: $\left.\chi^{2}(1)=51.30, p<0.001 ; H-H=H-M: \chi^{2}(1)=4.52, p=0.034\right)$. We find a significant difference between homogeneous villages and fragmented villages among the Muslim sample $(M-M \times H o m o g V i l=0, z=-9.25, p<0.001)$, but not in the Hindu sample $(H-H \times H o m o g V i l=0, z=-1.43, p=0.152)$.

Regression (2) extends our analysis to include village-level characteristics, individual attitudes, as well as responsiveness to characteristics such as caste and caste diversity within the session. The treatment effects remain broadly consistent with the restricted model. We find a small, positive and significant coefficient on Distance $H C$ : subjects villages which are isolated are more likely to cooperate. We find a negative and significant coefficient on VillIlit and VillUnemp: the higher a village's illiteracy rate or a village's unemployment rate, the lower the likelihood cooperation. In contrast, the coefficient on VillPop is extremely small and not significant. Irrespective of village size, the socio-economic status of a village is strongly correlated with cooperation.

Our measure of out-group attitudes has limited predictive power: we find a small and marginally significant coefficient on $D i s O G_{i}$, and no significant coefficients on any of its interactions. With regards to caste effects, we find a negative, but non-significant coefficient on both PropMyCaste Pr $_{i}$ and its interaction with the dummy for advantaged caste members, $A d v$. In other words, caste homogeneity appears not to influence behavior in the PD game.

Regression (3) performs the same analysis as regression (1), this time on behavior in the SH game. Much like our earlier analysis, there is a much less pronounced difference in and minimum effort games, respectively. 


\begin{tabular}{|c|c|c|c|c|c|c|c|c|}
\hline \multirow{3}{*}{$\frac{\mathrm{DV}: C_{i}}{M-M}$} & \multicolumn{4}{|c|}{$(\mathrm{PD})$} & \multicolumn{4}{|c|}{$(\mathrm{SH})$} \\
\hline & \multicolumn{2}{|c|}{$(1)$} & \multicolumn{2}{|c|}{$(2)$} & \multicolumn{2}{|c|}{$(3)$} & \multicolumn{2}{|c|}{$(4)$} \\
\hline & $2.59^{* * *}$ & $(0.20)$ & $3.37^{* * *}$ & $(0.52)$ & 0.95 & $(0.58)$ & -0.66 & $(0.42)$ \\
\hline$M-M \times H o m o g V i l$ & $-2.45^{* * *}$ & $(0.26)$ & $-3.35^{* * *}$ & $(0.42)$ & $-0.81^{* *}$ & $(0.39)$ & 0.43 & $(0.37)$ \\
\hline$H-H$ & $1.41^{* * *}$ & $(0.38)$ & $0.85^{* * *}$ & $(0.24)$ & $1.05^{* *}$ & $(0.51)$ & $1.11^{* * *}$ & $(0.26)$ \\
\hline$H-H \times H o m o g V i l$ & -0.62 & $(0.44)$ & $-1.14^{* * *}$ & $(0.36)$ & $-0.57^{* *}$ & $(0.27)$ & $-0.88^{* * *}$ & $(0.27)$ \\
\hline$H-M$ & 0.48 & $(0.34)$ & 0.52 & $(0.42)$ & 0.66 & $(0.58)$ & $1.19^{* * *}$ & $(0.28)$ \\
\hline$H-M \times$ Muslim & -0.17 & $(0.58)$ & -0.83 & $(0.58)$ & -0.29 & $(0.25)$ & $-0.86^{* *}$ & $(0.36)$ \\
\hline Muslim & 0.39 & $(0.38)$ & $0.97^{* * *}$ & $(0.35)$ & $0.38^{* *}$ & $(0.15)$ & $0.43^{*}$ & $(0.24)$ \\
\hline DistanceHC & \multicolumn{2}{|c|}{-} & $0.05^{* * *}$ & $(0.02)$ & \multicolumn{2}{|c|}{-} & $0.04^{* *}$ & $(0.02)$ \\
\hline VillPop & \multicolumn{2}{|c|}{-} & $-2 \times 10^{-5}$ & $\left(2 \times 10^{-5}\right)$ & \multicolumn{2}{|c|}{-} & $-2 \times 10^{-6}$ & $\left(2 \times 10^{-5}\right)$ \\
\hline Villilit & \multicolumn{2}{|c|}{ - } & $-8.33^{* *}$ & $(3.54)$ & \multicolumn{2}{|c|}{-} & $7.51^{* * *}$ & $(2.12)$ \\
\hline VillUnemp & \multicolumn{2}{|c|}{-} & $-5.55^{* * *}$ & $(2.09)$ & \multicolumn{2}{|c|}{-} & $-3.05^{*}$ & $(1.75)$ \\
\hline$D_{i s} O G_{i}$ & \multicolumn{2}{|c|}{-} & $0.32^{*}$ & $(0.16)$ & \multicolumn{2}{|c|}{-} & 0.31 & $(0.24)$ \\
\hline $\operatorname{DisOG}_{i} \times$ Muslim & \multicolumn{2}{|c|}{-} & -0.59 & $(0.49)$ & \multicolumn{2}{|c|}{-} & 0.33 & $(0.41)$ \\
\hline $\operatorname{Dis} O G_{i} \times H-M$ & \multicolumn{2}{|c|}{-} & -0.21 & $(0.63)$ & \multicolumn{2}{|c|}{-} & $-1.01^{* * *}$ & $(0.38)$ \\
\hline DisOG $_{i} \times H-M \times$ Muslim & \multicolumn{2}{|c|}{-} & 1.32 & $(1.02)$ & \multicolumn{2}{|c|}{-} & 0.58 & $(0.60)$ \\
\hline PropMyCaste $_{i}$ & \multicolumn{2}{|c|}{-} & -0.25 & $(1.00)$ & \multicolumn{2}{|c|}{-} & $0.79^{* *}$ & $(0.42)$ \\
\hline PropMyCaste $_{i} \times A d v$ & \multicolumn{2}{|c|}{-} & -1.03 & $(0.98)$ & \multicolumn{2}{|c|}{-} & -0.58 & $(0.42)$ \\
\hline$K_{n o w A l l}$ & \multicolumn{2}{|c|}{-} & 0.14 & $(0.42)$ & \multicolumn{2}{|c|}{-} & -0.12 & $(0.28)$ \\
\hline Male $_{i}$ & \multicolumn{2}{|c|}{. } & 0.25 & $(0.29)$ & \multicolumn{2}{|c|}{. } & -0.35 & $(0.23)$ \\
\hline$A g e_{i}$ & \multicolumn{2}{|c|}{-} & 0.01 & $(0.01)$ & - & & -0.01 & $(0.01)$ \\
\hline Constant & -0.04 & $(0.18)$ & $6.27^{* * *}$ & $(1.36)$ & -0.59 & $(0.51)$ & -1.72 & $(1.64)$ \\
\hline$N$ & 51 & & & 13 & 51 & & & 15 \\
\hline Pseudo-R ${ }^{2}$ & 0.0 & & & 10 & 0. & & & 07 \\
\hline
\end{tabular}

Village-level clustered standard errors in parentheses. ${ }^{* * *},{ }^{* *},{ }^{*}$ : significance at $1 \%, 5 \%$ and $10 \%$ level.

Table 3: Logit estimates of the determinants of cooperation in the PD and SH games. 
treatments conducted in fragmented villages: the only significant difference in behavior is that between $H-H$ and $M I X$ : the coefficient on the $H-H$ dummy is positive and significant $(H-H=0: z=2.05, p=0.040)$. Like our earlier analysis, we find a significant effect of village fragmentation on in-group/in-group matches $(M-M \times H o m o g V i l=0: z=-2.08, p=0.038$; $H-H \times H o m o g V i l=0: z=-2.13, p=0.033)$.

Regression (4) extends the analysis of behavior in the SH game in the same way as regression (2) did for behavior in the PD game. Again, the treatment effects remain consistent with regression (3). We replicate the effects in the PD game analysis in that there is a positive and significant coefficient on $D i s t H C$, a negative and significant coefficient on VillUnemp, as well as a very small and non-significant coefficient on VillPop - we can therefore rule out, insofar as our sample is concerned, that village size is driving our results. Surprisingly, we find a positive and significant coefficient on VillUnemp.

While the coefficient on DisOG is not significant, its interaction with $H-M$ is negative and significant, though not its interaction with the Muslim dummy variable: subjects who express disliking their religious out- group are less likely to cooperate when matched with an out-group, irrespective of their actual religion. Finally, with regards to caste, we find a positive and significant coefficient on PropMyCaste , though not on PropMyCaste $_{i} \times A d v$. The bigger the proportion of people in the other side of the room (i.e. the set of potential matches) of the same caste as the decision-maker, the higher the likelihood of cooperation, irrespective of the decision-maker belonging to the advantages castes or not. We conjecture that the fact that this coefficient is only significant in the stag hunt regression may be due to the fact that beliefs play a more prominent role in the stag hunt than in the prisoners' dilemma: the more in-group members a subject potentially faces, the more confident he or she may be that they will play the cooperate strategy.

Observation 8: In both the PD and SH game, the likelihood of a subject cooperating decreases with village unemployment. There is no effect of village size on behavior in either game. Caste breakdown in a session is only correlated with behavior in the SH game. 


\section{Discussion}

We now discuss some of the results from our experiment, and we highlight some limitations in interpreting the data. Our first main result is that in both prisoners' dilemma and stag hunt games, cooperation rates in homogeneous villages among individuals of the same religion are no different than cooperation rates in our control treatment where the identity of matches is uncertain, which was conducted in fragmented villages. We relied on a quasiexperimental approach to measure the effect of fragmentation. This means we cannot make causal inferences from the treatment comparisons. A possible explanation for this result could lie in the fact that different villages develop different norms, which in turn manifest themselves in different levels of cooperation.

We conjecture that our result may be driven by the fact that a sense of group identity is only triggered in fragmented villages. In other words, a sense of identity is meaningful only when an out-group exists. Without it, that particular category ceases to be meaningful. Our result resonates with laboratory evidence that shows that, insofar as artificial identities go, they only affect behavior if sufficiently salient (Eckel and Grossman, 2005; Chakravarty and Fonseca, 2014). It is also consistent with field evidence on in-group biases in judicial decisions: Shayo and Zussman (2011) find strong evidence of ethnic (i.e. Arab or Jewish) ingroup biases in sentencing decisions in Israeli small claims courts. These biases are strongly correlated with the incidence of terrorist events in geographical proximity of the court. The authors argue that the incidence of terrorism is a catalyst for the saliency of the judges' ethnic identity.

Cooperation levels among people of the same religious group are higher in religiously fragmented villages than homogeneous ones. Furthermore, cooperation levels in the latter case are no different to the case where subjects do not know the identity of their match in fragmented villages. This effect is stronger in the prisoners' dilemma than in the stag hunt game. One possibility is that group identity triggers greater concerns over the welfare of in-group members, which is in line with dictator game evidence from different ethnic groups in postwar Bosnia (Whitt and Wilson, 2007), and consistent with the modeling approach by Chen and Li (2009) and Chen and Chen (2011). These papers model the effect 
of social identity through other-regarding preferences, and apply them to distribution and coordination games, respectively.

However, beliefs can also determine behavior in the prisoners' dilemma, since that game could be transformed into a coordination game in utility payoffs if subjects exhibit other-regarding preferences. Our design does not permit us to disentangling the way in which identity affects beliefs about other player's actions (or their preferences) from the effect identity has on preferences in a strategic setting in a clean way. This is an important future step in the research on the economics of social identity.

Another potential explanation for the difference in treatment effect size between the two games could be the different framings used in the two games: the prisoners' dilemma was framed as a contribution game, while the stag hunt instructions employed the hunting analogy used by Rousseau. We used these framings to facilitate subjects' understanding of the game after studying the feedback we obtained from pilot sessions, but it is possible that the different frames may explain part of the difference in treatment effects in the two games.

We find that Muslim subjects exhibit higher in-group favoritism than Hindus, albeit only in the prisoners' dilemma. This may be because Muslims are a significant minority in India, which could make their religious identity more salient. This is consistent with evidence from trust experiments ran in India and Bangladesh with Muslim and Hindu subjects (Gupta et al., 2013), as well as from earlier survey evidence in India (Tripathi and Srivastava, 1981).

Interestingly, in our data, the existence of positive favoritism towards one's group does not mean prejudice towards out-group members: the cooperation rates in fragmented villages when subjects play with out-group members are not lower than those in the control treatment in either game. This leads to the intriguing finding of our experiment: religiouslydiverse villages exhibit higher cooperation rates.

Of course, there could be other drivers of behavior which are beyond the control of our experimental design. While we control for as many observable characteristics (both at the village and individual levels) as possible in our econometric analysis, it is possible that behavior in our experiment could be driven by non-controlled factors. This, added to the small number of villages in our data set urges a degree of caution when attributing effects to social identity effects alone. One of the interesting effects our econometric model picked up 
was the effect of relative isolation: the likelihood of cooperation in both games was positively correlated with how distant a village was from a health center. This result suggests that social capital is an important driver of behavior: the more isolated a community is, the greater the need to establish cooperation norms and/or risk sharing arrangements within the community, particularly in the context of repeated interaction.

While our paper focuses primarily on religion, caste is another important identity in Indian society. The caste system in India is incredibly complex, and we draw inferences about its effect with great caution. In any event, we could only collect data on three caste-related social groups who benefit from constitutional recognition and for whom there are affirmative action policies in place: Scheduled Castes, Scheduled Tribes and Other Backward Classes. Our estimation results suggest that the proportion of individuals of the same caste as the decision-maker in the pool of possible matches is positively and significantly correlated with cooperation rates in the stag hunt, but no statistically significant correlation exists in the prisoners' dilemma. PropMyCaste could be a proxy of beliefs: I believe my social group is more likely to cooperate, so the more in-group members are in the pool of potential matches, the more likely it is that I will want to cooperate. While the belief dimension exists in both games, it exists in a more direct way in the stag hunt game, and we conjecture that this could be the reason for the effect being significant in that game.

It is interesting to compare the results of our cooperation games with the results from the Tullock game, which are presented in our companion paper, Chakravarty et al. (2015). In the Tullock game, pairs of subjects competed for a prize of INR 80, and they could spend any amount from zero up to INR 80 in multiples of 20. Unlike the two cooperation games, neither the degree of village fragmentation nor the identity of the match (in fragmented villages) had any significant impact on rent-seeking behavior. In all treatments, the mean expenditure level is slightly above the risk-neutral Nash equilibrium level of INR 20, although the median expenditure level is the Nash equilibrium one. In other words, as far as our sample, the degree of fragmentation has a greater impact on cooperation levels rather than rent-seeking expenditures. We conjecture that the lack of sensitivity to fragmentation/match type may be due to the action space available to subjects being coarse: subjects may have preferred to spend amounts which were not available (e.g. INR 30) and therefore opted for 
the next lowest available amount (i.e. INR 20). While it is interesting that behavior in a competitively-framed environment produced very different results to games framed in a cooperative way, we are wary to offer definitive interpretations to this result. The Tullock contest always followed the Prisoners' Dilemma and Stag Hunt games in all sessions, and there could have been hedging behavior.

\section{Conclusion}

Social identity theory has been identified as a potential cause for the negative correlation between the degree of social fragmentation and economic performance, particularly the provision of public goods (Alesina and La Ferrara, 2000; 2005). The argument is that individuals derive benefit from membership of social groups and display favoritism towards members of their group at the potential detriment of outsiders. As societies become more fragmented, discrimination along group lines means less cooperation with a larger number of outsiders, leading to lower economic performance.

However, there is still a lack of micro-level data which establishes the extent to which social identity drives this correlation. Our paper reports data from an artefactual field experiment in which we compare cooperative behavior between religiously fragmentated villages and religiously-homogenous villages in a region of the world where religion is an integral part of society and inter-religious conflict is well documented. We sample our participants from villages whose populations are predominantly of one religion, as well as villages whose populations are roughly equally split between the two religions.

Our evidence suggests that, insofar as religious identities, fragmentation does not lead to lower cooperation. In fact, we find the opposite relationship: residents of religiously diverse villages are more cooperative than those who reside in homogeneous villages. The increase in cooperation levels is driven by higher cooperation rates with in-group members: in fragmented villages social identity preferences manifest themselves primarily through greater in-group favoritism, rather than out-group derogation.

It is possible that the explanation for the negative relationship between fragmentation and economic performance established in the literature (Alesina and La Ferrara, 2005) lies 
in institutions. These include the ability of social groups not only to monitor compliance more effectively, but also to punish non-compliant individuals more effectively (Greif, 1993). In small communities, mechanisms like ostracism are likely to be easier to enforce. Miguel and Gugerty (2005) find that schools in ethnically-fragmented communities in Kenya have significantly lower local funding that schools in homogeneous areas. They attribute this to social sanctioning of free-riders being more effective in ethnically-homogeneous villages. Central to this argument is a repeated-game argument in which sanctions work not only as a punishment for past and present actions, but also as a deterrent to bad behavior in the future. This is a plausible and viable mechanism in these villages, where intra-religious community ties are very strong. La Ferrara (2003) shows that group affiliation implies a larger set of cooperation strategies, as reciprocal punishment can be targeted not only to defectors, but also to their fellow in-group members.

This is not to say that the harsher punishment of norm violators is not consistent with a sense of identity. It is certainly possible that the social sanctions towards free-riders by Kenyan parents were driven by a strong sense of community belonging — in itself a powerful identity. Goette et al. (2006) show that Swiss army personnel are willing to punish defectors in a prisoners' dilemma game with third-party punishment, particularly so when the victim of defection is a fellow platoon member. Social identity preferences likely work through institutions, amplifying the effect of social sanctions by reducing the utility cost of punishing someone, as well as increasing the cost of being punished by one's peers. The net effect could be that cooperation is more appealing in the long run. This is consistent with the fact that in smaller communities, ostracism and exclusion are common punishment mechanisms. Understanding how identity interacts with such institutions is a promising future line of inquiry.

\section{References}

[1] Akbar, M. J. 2003. Riot after riot: Reports on caste and communal violence in India. New Delhi: Roli Books 
[2] Akerlof, G.A., and Kranton, R.E. 2000. Economics and identity. Quarterly Journal of Economics 115(3), 715-753.

[3] Alesina, A., Baqir, R., and Easterly, W., 1999. Public goods and ethnic divisions. Quarterly Journal of Economics 114(4), 1243-1284.

[4] Alesina, A., Devleeschauwer, A., Easterly, W., Kurlat, S., and Wacziarg, R., 2003. Fractionalization. Journal of Economic Growth 8(2), 155-194.

[5] Alesina, A., and La Ferrara, E., 2000. Participation in heterogeneous communities. Quarterly Journal of Economics 115(3), 847-904.

[6] Alesina, A., and La Ferrara, E., 2005. Ethnic diversity and economic performance. Journal of Economic Literature 43, 762-800.

[7] Allport. G. 1954. The Nature of Prejudice. Cambrige, Mass: Addison-Wesley.

[8] Anderson, S. 2011. Caste as an impediment to trade. American Economic Journal: Applied Economics 3(1), 239-263.

[9] Andreoni, J., 1990. Impure altruism and donations to public goods: A theory of warmglow giving. Economic Journal 100, 464-477.

[10] Banerjee, A., Iyer, L., and Somanathan, R., 2005. History, social divisions, and public goods in rural India. Journal of the European Economic Association 3(2-3), 639-647.

[11] Bardhan, P.K., Mookherjee, D., and Torrado, M.P., 2010. Impact of political reservations in West Bengal local governments on anti-poverty targeting. Journal of Globalization and Development 1(1), 1-38.

[12] Basu, K. 2007. Participatory Equity, Identity, and Productivity: Policy Implications for Promoting Development. Cornell University Center for Analytic Economics Working Paper 0605. http://ssrn.com/abstract $=956080$.

[13] Bernhard, H., Fehr, E., Fischbacher, U., 2006. Group affiliation and altruistic norm enforcement. American Economic Review 96(2), 217-221. 
[14] Bhattacharya, P.C., 2000. An analysis of rural-to-rural migration in India. Journal of International Development 12, 655-667.

[15] Brass, P. R. 2003. The production of Hindu-Muslim violence in contemporary India. Seattle: University of Washington Press.

[16] Brewer, M.B. 1986. Ethnocentrism and its role in inter temporal trust. In M. Brewer and B. Collins (Eds.) Scientific inquiry and the social sciences: A volume in honor of Donald T. Campbell, 345-360. San Francisco, CA: Jossey-Bass.

[17] Brewer, M.B. 1991. The Social Self: On Being the Same and Different at the Same Time. Personality and Social Psychology Bulletin 17(5), 475-482.

[18] Brewer, M.B. 1999. The Psychology of Prejudice: Ingroup Love or Outgroup Hate? Journal of Social Issues 55(3), 429-444.

[19] Capraro, V., Jordan, J.J., and Rand, D.G. 2014. Heuristics guide the implementation of social preferences in one-shot Prisoner's Dilemma experiments. Nature Scientific Reports 4, doi:10.1038/srep06790.

[20] Chakravarty, S. and Fonseca, M.A. 2014. The Effect of Social Fragmentation on Public Good Provision: An Experimental Study. Journal of Behavioral and Experimental Economics 53, pp. 1-9.

[21] Chakravarty, S., Fonseca, M.A., Ghosh, S. and Marjit, S. 2015. Religious fragmentation, social identity and rent-seeking: Evidence from an artefactual field experiment in India. University of Exeter Economics Department Discussion Papers Series, No. 15/12.

[22] Charness, G., Rigotti, L. and Rustichini, A. 2007. Individual behavior and group membership. American Economic Review 97(4), 1340-1352.

[23] Chen, Y., Chen, R. 2011. The potential of social identity for equilibrium selection. American Economic Review 101(6), 2562-2589.

[24] Chen, Y., Li, S.X. 2009. Group identity and social preferences. American Economic Review 99(1), 431-457. 
[25] Cooper, R. 1999. Coordination Games: Complementarities and Macroeconomics. Cambridge; New York and Melbourne: Cambridge University Press.

[26] Das. P.K., Kar, S., Kayal, M., 2011. Religious Minorities and Provision of Public Goods: Evidence from Rural West Bengal. IZA Discussion Paper No. 6154.

[27] Dawes, R.M. 1980. Social dilemmas. Annual Review of Social Psychology 31, 169-193.

[28] Easterly, W. and Levine, R. 1999. Africa's growth tragedy: Policies and ethnic divisions. Quarterly Journal of Economics 112(4), 1203-1250.

[29] Eckel, C.C. and Grossman, P.J. 2005. Managing diversity by creating team identity. Journal of Economic Behavior and Organization 58, 371-392.

[30] Fehr, E. and Schmidt, K. 1999. A Theory of Fairness, Competition and Cooperation. Quarterly Journal of Economics 114(3), 817-868.

[31] Fershtman, C., Gneezy, U., 2001. Discrimination in a segmented society: An experimental approach. Quarterly Journal of Economics 116(1), 351-377.

[32] Goette, L., Huffman, D., Meier, S., 2006. The Impact of Group Membership on Cooperation and Norm Enforcement: Evidence Using Random Assignment to Real Social Groups. American Economic Review 96(2), 212-216.

[33] Greif, A. 1993. Contract enforceability and economic institutions in early trade: The Maghribi traders' coalition. American Economic Review 83(3), 525-548.

[34] Gupta, G., Mahmud, M., Maitra, P., Mitra, S., and Neelim, A. 2013. Religion, Minority Status and Trust: Evidence from a Field Experiment. Monash Economics Working Papers $28-13$.

[35] Habyarimana, J., Humphreys, M., Posner, D.N., Weinstein, J.M., 2007. Why does ethnic diversity undermine public goods provision? American Political Science Review 101(4), 709-725. 
[36] de Hann, A. 1997. Poverty and Social Exclusion: A Comparison of Debates on Deprivation, PRUS Working Papers, No.2, Poverty Research unit at Sussex, University of Sussex, Falmer, Brighton, U.K.

[37] Isaac, R.M., Walker, J.M., Williams, A.W. 1994. Group size and the voluntary provision of public goods: Experimental evidence using large groups. Journal of Public Economics $54,1-36$.

[38] John, R.M., and Mutaktar, R. 2005. Statewise estimates of poverty among religious groups in India. Economic and Political Weekly 40(13), 1337+1339-1345.

[39] Klor, E.F., Shayo, M. 2010. Social identity and preferences over redistribution. Journal of Public Economics 94(3-4), 269-278.

[40] Kreps, D.M., Milgrom, P., Roberts, J., and Wilson, R. 1992. Rational cooperation in the finitely repeated prisoners' dilemma. Journal of Economic Theory 27, 245-252.

[41] La Ferrara, E. 2003. Kin Groups and Reciprocity: A Model of Credit Transactions in Ghana. American Economic Review 93(5), 1730 ?51.

[42] Miguel, E., and Gugerty, M.K. 2005. Ethnic Diversity, Social Sanctions, and Public Goods in Kenya. Journal of Public Economics 89 (11-12), 2325-2368.

[43] Mitra, A., Ray, D., 2013. Implications of an economic theory of conflict: Hindu-Muslim violence in India. Journal of Political Economy 122(4), 719-765.

[44] Morita, H. and Servátka, M. 2013. Group identity and relation-specific investment: An experimental investigation. European Economic Review 58, 95-109.

[45] New York Times, 6th June 2014. Timeline of the Riots in Modi's Gujarat. http://www.nytimes.com/interactive/2014/04/06/world/asia/modi-gujarat-riotstimeline.html?. Last retrieved, 15th January, 2015.

[46] Poterba, J., 1998. Demographic change, intergenerational linkages, and public education. American Economic Review 88(2), 315-320. 
[47] Posner, R.A., 1998. Creating a legal framework for economic development. World Bank Research Observer 13(1), 1-11.

[48] Reuben, E., and Riedl, A. 2013. Enforcement of contribution norms in public good games with heterogeneous populations. Games and Economic Behavior 77(1), 122-137.

[49] Roth, A.E., 1988. Laboratory Experimentation in Economics: A Methodological Overview. Economic Journal 98, 974-1031.

[50] Sachar Committee Report. 2006. Social, Economic and Educational Status of the Muslim Community of India: A Report. Prime Ministers High Level Committee, Cabinet Secretariat, Government of India.

[51] Sally, D., 1995. Conversation and cooperation in social dilemmas: A meta-analysis of experiments from 1958 to 1992. Rationality and Society 7, 58-92.

[52] Sen, A.K. 2000. Social Exclusion: Concept, Application and Scrutiny. Office of Environment and Social Development, Asian Development Bank, Social Development Papers.

[53] Shayo, M. and Zussman, A. Judicial ingroup bias in the shadow of terrorism. Quarterly Journal of Economics 126(3), 1447-1484.

[54] Skyrms, B. 2001. The Stag Hunt. Proceedings and Addresses of the American Philosophical Association 75(2), 31-41.

[55] Smith, A. 2011. Group composition and conditional cooperation. Journal of SocioEconomics 40(5), 616- 622 .

[56] Tajfel, H., Billig, M.G., Bundy, R.P., Flament, C., 1971. Social categorization in intergroup behavior. European Journal of Social Psychology 1(2), 149-178.

[57] Times of India. 8th September 2010. Communal clash near Bangla border, Army deployed. http://timesofindia.indiatimes.com/india/Communal-clash-near-Banglaborder-Army-deployed/articleshow/6516123.cms?referral=PM. Last retrieved, 15th January, 2015. 
[58] Tripathi, R.C, and Srivastava, R. 1981. Relative deprivation and intergroup attitudes. European Journal of Social Psychology 11(3), 313-318.

[59] Turner, J.C. and Brown, R. J. 1978. Social Status, Cognitive Alternatives and Intergroup Relations. In Tajfel, H. (ed.) Differentiation between Social Groups. London: Academic Press.

[60] Yamagishi, T. and Kiyonari, T. 2000. The group as the container of generalized reciprocity. Social Psychology Quarterly 63, 116-132.

[61] Weber, R.A. 2006. Managing growth to achieve efficient coordination in large groups. American Economic Review 96(1), 114-126.

[62] Whitt, S., and Wilson, R.K. 2007. The dictator game, fairness and ethnicity in postwar Bosnia. American Journal of Political Science 51(3), 655-668.

\section{A Appendix - For Online Publication}

\section{A.1 Subject Characteristics}

In this section, we outline the basic characteristics of our sample. In particular, we wish to understand whether the participant subsample from homogeneous villages differs in a systematic way than the subsample from fragmented villages. To this effect, we compare the two types of villages, pooling the two types of homogeneous villages on a number of characteristics, including caste, marital status, place of birth (both the subjects and their next-of-kin), land ownership, profession, and literacy level.

Table 4 displays the proportion of subjects in each type of village that belong to each of 37 categories. We do not find large discrepancies on any category, although some of the differences are statistically significant using Fisher's exact test. The two differences that are worthy of note are the proportion of advantaged caste subjects, which is ten percentage points higher in Homogeneous villages, while OBC subjects are more prevalent by eight percentage points in Fragmented villages. We also sampled more subjects who either finished or were enrolled in tertiary education in Homogeneous villages. Nevertheless, we reiterate that we 
do not find systematic differences across multiple categories; even those categories where we there are significant differences, these are not sufficiently large to warrant concern.

\section{A.2 Methodological Note}

Before reproducing the experimental materials, a methodological note is warranted. A large proportion of our participant sample was unable to read and/or write to a satisfactory level of proficiency. Around a third of our sample was completely unable to read or write and a further $17 \%$ only had basic primary education. As such, we had to describe the different games in a different way than that used in typical laboratory experiments. We took a number of design decisions, which we describe and justify in turn.

We opted not to present any payoff matrix to participants. Based on early pilots, we felt that a payoff matrix (even in simple $2 \times 2$ games) would be too confusing and abstract to many participants. Instead, we presented the game to participants using a simple, but familiar framing. We then enumerated the actions available to participants, and we described each contingency in the game in turn using visual aids. To circumvent the illiteracy problem, payoffs were described using rupee notes and coins, since all participants were familiar with currency.

We framed the Prisoners' Dilemma game as a two-player voluntary contribution game in which any contribution to a common pool is multiplied by 1.5 and divided equally among both players. We felt this was the most natural way to explain the game. We framed the Stag Hunt game in the vein of Rousseau's original fable which originated the game itself. We used fish, since fishing is a more common activity in West Bengal than hunting and therefore the analogy would be more meaningful.

We piloted these framings in a study with a group of participants in the Birbhum district who had the same socio-economic background as our main subject pool. The feedback we obtained from post-session interviews suggested that our choice of framing led to participants understanding the incentive structure of each game without leading to experimenter demand effects. It is possible that our choice of framing could have led participants to interpret games in unintended ways, but we feel that participant confusion would be a worse outcome. Furthermore, since we are interested in differences in cooperation levels 


\begin{tabular}{|c|c|c|c|}
\hline Variable & "Fragmented Villages & Homogeneous Villages & p-value \\
\hline Male & 0.45 & 0.49 & 0.374 \\
\hline Age & $35.24(12.26)$ & $33.52(13.05)$ & 0.127 \\
\hline $\mathrm{SC}$ & 0.18 & 0.20 & 0.821 \\
\hline $\mathrm{ST}$ & 0.00 & 0.02 & 0.168 \\
\hline $\mathrm{OBC}$ & 0.16 & 0.08 & 0.003 \\
\hline Advantaged Castes & 0.60 & 0.70 & 0.020 \\
\hline Single & 0.18 & 0.24 & 0.098 \\
\hline Married & 0.77 & 0.71 & 0.188 \\
\hline Widowed & 0.04 & 0.04 & 0.823 \\
\hline Divorced & 0.01 & 0.01 & 0.640 \\
\hline Separated & 0.00 & 0.01 & 0.425 \\
\hline No Family Status & 0.00 & 0.00 & 1.000 \\
\hline Born Here & 0.69 & 0.71 & 0.699 \\
\hline Spouse Born Here & 0.42 & 0.43 & 0.787 \\
\hline Father Born Here & 0.65 & 0.69 & 0.346 \\
\hline $\begin{array}{l}\text { Landless } \\
\text { Contracted Labourer }\end{array}$ & 0.01 & 0.03 & 0.179 \\
\hline Landless Farmer & 0.12 & 0.15 & 0.294 \\
\hline $\begin{array}{l}\text { Landless } \\
\text { Non-contracted Labourer }\end{array}$ & 0.11 & 0.05 & 0.011 \\
\hline Landed Less $0.5 \mathrm{H}$ & 0.06 & 0.05 & 0.711 \\
\hline Landed Less 1H & 0.08 & 0.06 & 0.500 \\
\hline Landed More $1 \mathrm{H}$ & 0.03 & 0.04 & 0.804 \\
\hline Seamstress & 0.09 & 0.09 & 0.877 \\
\hline Student & 0.08 & 0.15 & 0.024 \\
\hline Office Worker & 0.02 & 0.02 & 0.739 \\
\hline Unemployed & 0.03 & 0.06 & 0.048 \\
\hline Housewife & 0.26 & 0.18 & 0.034 \\
\hline Attendant & 0.03 & 0.01 & 0.080 \\
\hline Tutor House & 0.01 & 0.01 & 1.000 \\
\hline Healthworker & 0.00 & 0.00 & 1.000 \\
\hline Govt Rep & 0.03 & 0.01 & 0.080 \\
\hline Quack & 0.01 & 0.00 & 0.510 \\
\hline Tobacco Worker & 0.03 & 0.10 & $<0.001$ \\
\hline Other & 0.01 & 0.01 & 1.000 \\
\hline Retired & 0.00 & 0.01 & 0.076 \\
\hline Illiterate & 0.20 & 0.19 & 0.911 \\
\hline Sign Name & 0.13 & 0.11 & 0.498 \\
\hline Primary Education & 0.15 & 0.14 & 0.802 \\
\hline Secondary Education & 0.41 & 0.39 & 0.716 \\
\hline Tertiary Education & 0.10 & 0.17 & 0.026 \\
\hline
\end{tabular}

Standard deviations in paretheses.

p-values refer to 2-sided Fisher's exact tests except for "Age", where they refer to 2-sided t-test.

Table 4: Subject characteristics as a function of village type. 
across village-types, rather than cooperation levels per se, we think this issue is of limited importance.

\section{A.3 Instructions}

The following instructions are the English translations from Bengali. Experimenters read them aloud to participants as a fixed script. The team of experimenters used large A1-sized sheets mounted in the middle of the room to assist them in explaining every contingency of each game. The text in bold inside square brackets indicates an action by the experimenter, and was not part of the script. We include the example sheets along with the main text for ease of exposition. We also include the decision forms in separate sub-sections.

\section{A.3.1 Preamble}

Welcome to our session. In this session, we will ask you to make series of decisions.

This session is part of a large study sponsored by a university. The purpose of this study is to understand how people make decisions in a typical Indian village. The objective is to better understand how to improve the welfare of villagers in India.

The decisions you will make are not a test of your knowledge. There is no right or wrong way to decide. What we want to know is how you decide when faced with slightly different problems. These problems give you the chance of earning a significant amount of money, so please think carefully before making your decisions.

Please do not talk either to the people sitting next to you or the people across the room about the task. If you have any questions about the experiment, or if something does not make sense, please raise your hand, and one of my colleagues will take your question.

The money you earn will depend on what you choose, on what other people in the room choose and sometimes depending on chance.

We will first explain to you carefully the nature of each decision, and how your payment is determined in each decision. This will involve some examples. Please pay attention to the rules. If you have any question or if the rules are difficult to understand, please ask. It is very important to us that you understand how each decision works. 
You will make your decisions on a piece of paper, which we will provide. Please make sure you fill all the necessary decisions, since these will be what determines your payment for the session.

The pieces of paper you will receive will have a number. This number is unique to you. We will pay you based on your number. Please do not write your name on the piece of paper. That way, no one will ever be able to link the decisions you make in this session to you.

Your payment for each task will be determined at the end of the session. You will then be paid in cash. While you are collecting your cash we will also do a brief questionnaire with each of you individually.

\section{A.3.2 PD Game Instructions}

In this task you will be paired with someone across the room. You will only be paired with that person for this decision; you will never be paired with that person again in this session. In this task, we will give you 40 rupees. The person with whom you are paired will also receive 40 rupees. You can either keep the 40 rupees or put them in a joint account with the other person. The person with whom you are paired has to make the same choice as you. We will put an additional 20 rupees for each 40 rupees you or the other person puts in the joint account. You will receive half of what is in the joint account, regardless of how much you put in.

- If you put 40 rupees in the joint account and the other person also puts 40 rupees in the joint account, you will receive 60 rupees and the other person will also receive 60 rupees.

- If you put 40 rupees in the joint account and the other person puts nothing, you will receive 30 rupees and the other person will receive 70 rupees.

- If you put nothing in the joint account and the other person puts 40 rupees, you will receive 70 rupees and the other person will receive 30 rupees.

- If you and the other person put nothing in the joint account, you will receive 40 rupees and the other person will also receive 40 rupees. 
Both you and the other person must choose at the same time. This means you will not know what the other person has chosen while making your own choice.

Let's go through a couple of examples, using my colleague $[\mathrm{X}]$ and $[\mathrm{Y}]$ as "pretend" players.

\section{Example 1:}

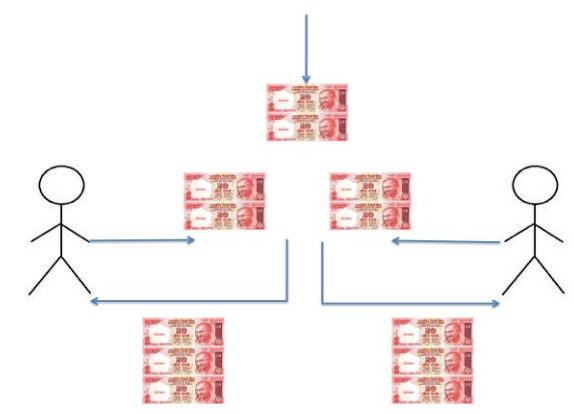

Figure 5: Accompanying A1-size sheet to Example 1.

The sheet on the wall shows the first example we would like to go through with you.

Suppose $[\mathrm{X}]$ decides to put his 40 rupees in the joint account, and $[\mathrm{Y}]$ does the same. That means the total put by both people is 80 rupees. We will add another 40 rupees to the total, which becomes 120 rupees.

We then split the total equally between the two people. So,

\section{[TRY TO ELICIT ANSWER FROM A PARTICIPANT!]}

$[\mathrm{X}]$ gets 60 rupees and $[\mathrm{Y}]$ gets 60 rupees.

\section{Example 2:}

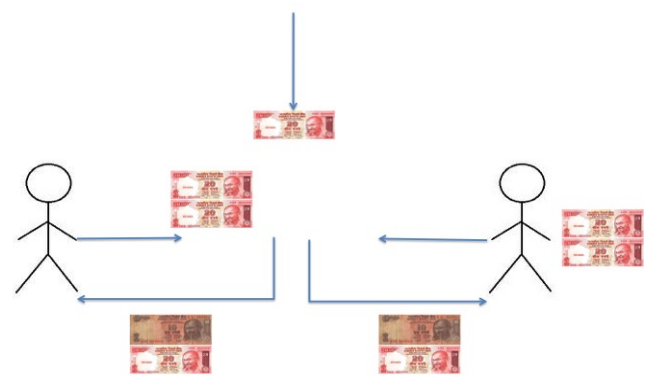

Figure 6: Accompanying A1-size sheet to Example 2. 
The sheet on the wall shows the second example we would like to go through with you.

Suppose $[\mathrm{X}]$ decides to put his 40 rupees in the joint account, but [Y] does not do the same. That means the total put by both people is 40 rupees. We will add another 20 rupees to the total, which becomes 60 rupees.

We then split the total equally between the two people. So,

\section{[TRY TO ELICIT ANSWER FROM A PARTICIPANT!]}

$[\mathrm{X}]$ gets 30 rupees and $[\mathrm{Y}]$ gets 70 rupees: 30 from the joint account, plus the 40 rupees she kept.

\section{Example 3:}

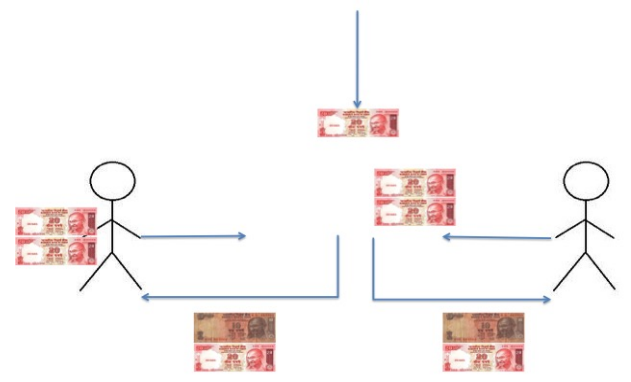

Figure 7: Accompanying A1-size sheet to Example 3.

The sheet on the wall shows the third example we would like to go through with you.

Suppose $[\mathrm{X}]$ decides not to put his 40 rupees in the joint account, while [Y] decides to put his 40 rupees in the joint account. That means the total put by both people is 40 rupees. We will add another 20 rupees to the total, which becomes 60 rupees.

We then split the total equally between the two people. So,

\section{[TRY TO ELICIT ANSWER FROM A PARTICIPANT!]}

$[\mathrm{Y}]$ gets 30 rupees and $[\mathrm{X}]$ gets 70 rupees: 30 from the joint account, plus the 40 rupees he kept.

\section{Example 4:}

The sheet on the wall shows the fourth example we would like to go through with you. 


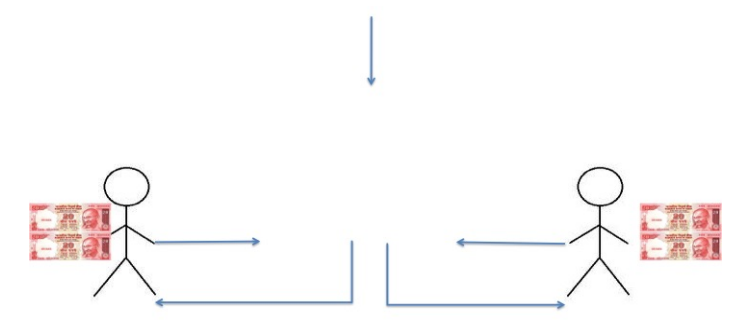

Figure 8: Accompanying A1-size sheet to Example 4.

Suppose $[\mathrm{X}]$ decides keep his 40 rupees in the joint account, and [Y] does the same. That means the total put by both people in the joint account is 0 rupees. Since nobody put any money in the joint account, we add nothing to the joint account. Therefore,

\section{[TRY TO ELICIT ANSWER FROM A PARTICIPANT!]}

$[\mathrm{X}]$ gets 40 rupees and $[\mathrm{Y}]$ also gets 40 rupees.

\section{ANY QUESTIONS? (wait for a few seconds)}

In your decision sheet, please choose now how much money you want to put in the joint account.

[Experimenters should now hand the decision sheet to the subject]

\section{A.3.3 PD Game Decision Form}
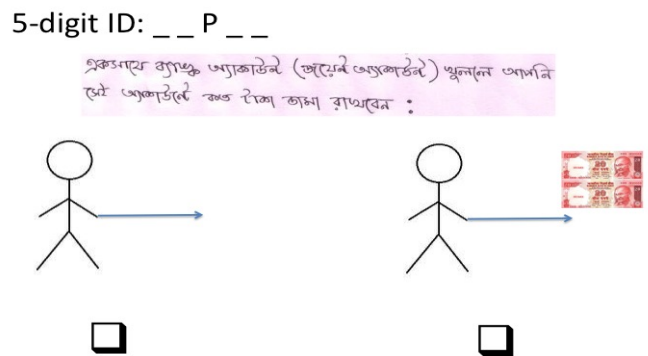

Figure 9: Decision form for the PD game. Bengali script over the decision form states: "If you open a (joint) bank account, then how much will you contribute to account:" 


\section{A.3.4 SH Game Instructions}

In this task you will be paired with someone across the room. You will only be paired with that person for this game; you will never be paired with that person again in this session. In this task you and person with whom you are matched will have to make a decision. Your payment for this task will depend on what you choose and what the other person chooses. You and the other person have to hunt a fish. You may choose to hunt a small fish or a large fish. The large fish is difficult to hunt. In order to hunt it, you need the other person to hunt it with you at the same time. The small fish is easy to hunt. You can hunt it by yourself.

- If you decide to hunt the small fish, you will earn 40 rupees, no matter what the other person chooses.

- If you decide to hunt the large fish and the other person also decides to hunt the large fish, you will earn 80 rupees and the other person also earns 80 rupees.

- If you decide to hunt the large fish and the other person decides to hunt the small fish, you will earn 0 rupees and the other person earns 40 rupees.

Both you and the other person must choose which fish to hunt at the same time. This means you will not know what the other person has chosen while making your own choice.

Lets go through a few examples using my colleagues.

\section{Example 1:}

The sheet on the wall shows the first example we would like to go through with you. Suppose $[\mathrm{X}]$ hunts the small fish and $[\mathrm{Y}]$ hunts the small fish. In that case,

\section{[TRY TO ELICIT ANSWER FROM A PARTICIPANT!]}

$[\mathrm{X}]$ gets 40 rupees and [Y] gets 40 rupees.

\section{Example 2:}

The sheet on the wall shows the second example we would like to go through with you. Suppose $[\mathrm{X}]$ hunts the small fish and $[\mathrm{Y}]$ hunts the large fish. In that case, 


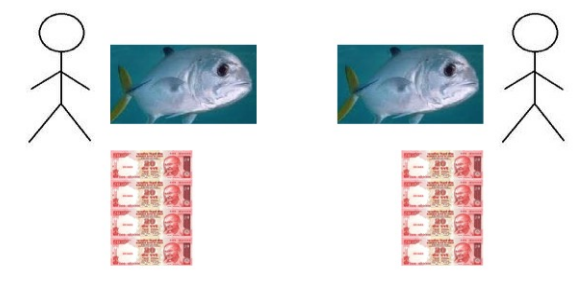

Figure 10: Accompanying A1-size sheet to Example 1.

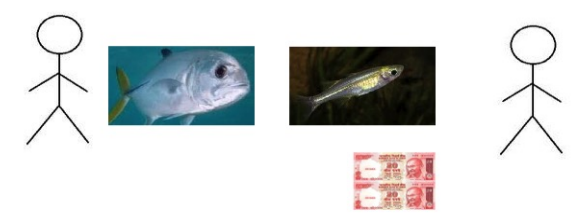

Figure 11: Accompanying A1-size sheet to Example 2.

\section{[TRY TO ELICIT ANSWER FROM A PARTICIPANT!]}

$[\mathrm{X}]$ gets 40 rupees and $[\mathrm{Y}]$ gets 0 rupees.

\section{Example 3:}

The sheet on the wall shows the third example we would like to go through with you.

Suppose $[\mathrm{X}]$ hunts the large fish and $[\mathrm{Y}]$ hunts the small fish. In that case,

\section{[TRY TO ELICIT ANSWER FROM A PARTICIPANT!]}

$[\mathrm{X}]$ gets 0 rupees and $[\mathrm{Y}]$ gets 40 rupees.

\section{Example 4:}

The sheet on the wall shows the fourth example we would like to go through with you. Suppose $[\mathrm{X}]$ hunts the large fish and $[\mathrm{Y}]$ hunts the large fish. In that case, [TRY TO ELICIT ANSWER FROM A PARTICIPANT!]

$[\mathrm{X}]$ gets 80 rupees and $[\mathrm{Y}]$ gets 80 rupees. 


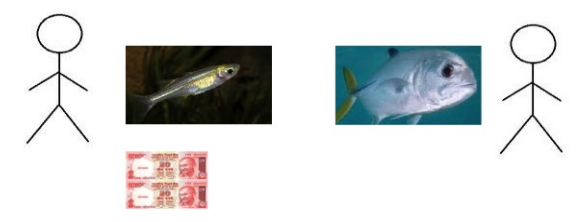

Figure 12: Accompanying A1-size sheet to Example 3.

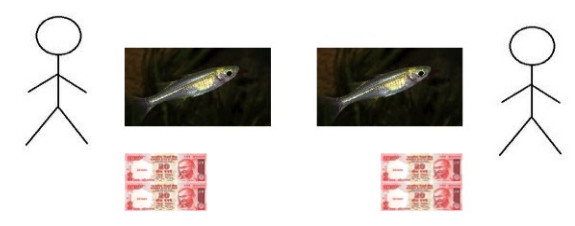

Figure 13: Accompanying A1-size sheet to Example 4.

ANY QUESTIONS? (wait for a few seconds)

In your decision sheet, please choose the fish (small or large) you want to catch.

[Experimenters should now hand the decision sheet to the subjects]

\section{A.3.5 SH Game Decision Form}




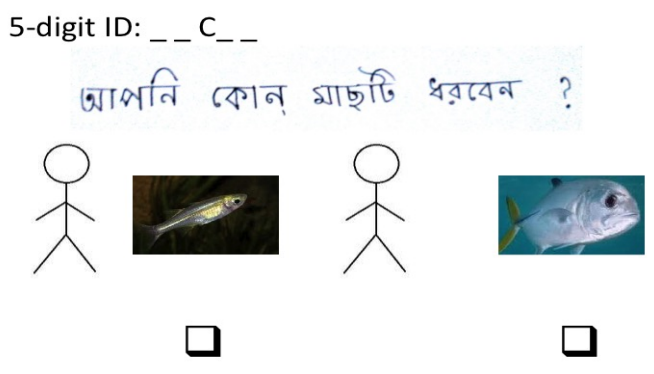

Figure 14: Decision form for the SH game.Bengali script over the decision form states: "Which fish would you like to catch?"

\section{A.4 Post-experimental Questionnaire}

After all participants completed the final task and the experimenter team collected all decision materials, participants were called individually to a separate room where they were asked a number of survey questions, prior to knowing the outcome of each game and receiving their payoff. Table 5 outlines each question, along with summary statistics.

\begin{tabular}{ll}
\hline \hline Question Text & Category/Domain \\
\hline Age & {$[16,80]$} \\
\hline Religion & $\{$ Hindu, Muslim, Christian, Sikh, \\
\hline Caste & Buddhist, Parsi, Other $\}$ \\
\hline Marital Status & $\{$ SC, ST, OBC, Normal, Other $\}$ \\
\hline Born in Village? & $\{$ Single, Married, Widowed, \\
\hline If not, how long have you lived here? & Divorced, Husband Left, Other $\}$ \\
\hline Spouse Born in Village? & $\{$ Yes, No, Don't Know $\}$ \\
\hline If not, how long has (s)he lived here? & $\{$ Yes, No, Don't Know $\}$ \\
\hline Father Born in Village? & \\
\hline If not, how long has he lived here? & $\{$ Yes, No, Don't Know $\}$ \\
\hline Grandfather Born in Village? & $\{$ Yes, No, Don't Know $\}$ \\
\hline
\end{tabular}


If not, how long has he lived here?

Education Level

\{lliterate, Sign Name, Dropped

out at grade $x$, Completed grade $x$,

Currently sitting grade $x$ \}

$\{$ Landless contract laborer, Landless

farmer, Landless non-contract

laborer, Attendant,

Small-property farmer $(<0.5 \mathrm{Ha})$,

Medium-property farmer $(<1 \mathrm{Ha})$,

Profession

Big-property farmer $>1 \mathrm{Ha}$ ),

Quarry worker, Student, Office worker,

Unemployed, Housewife, Tutor House,

Health Worker, Gov't employment

program, Village quack, Village tobacco

factory, Other\}

\begin{tabular}{ll}
\hline Does your village have a pond? & $\{$ Yes, No, Don't Know $\}$ \\
\hline Who owns it? & $\{$ Gov't, NGO, Village $\}$ \\
\hline Do you use it? & $\{$ Yes, No, Don't Know $\}$ \\
\hline Has it been appropriated/expropriated? & $\{$ Yes, No, Don't Know $\}$ \\
\hline
\end{tabular}

$\{$ Higher caste, Land-owning villagers,

If yes, by whom? Rich families, Political party,

Panchayat, Other

\begin{tabular}{ll}
\hline Does your village have a tubewell? & $\{$ Yes, No, Don't Know $\}$ \\
\hline Who owns it? & $\{$ Gov't, NGO, Village, \\
& Private individual, Don't Know $\}$
\end{tabular}

\begin{tabular}{ll}
\hline Do you use it? & $\{$ Yes, No $\}$ \\
\hline Has it been appropriated/expropriated? & $\{$ Yes, No, Don't Know $\}$ \\
\hline
\end{tabular}

If yes, by whom?

$\{$ Higher caste, Land-owning villagers,

Rich families, Political party, 
Panchayat, Other

How far is the Block Health Center?

\{Dispensary, Primary Health Center,

If you fall ill, where do you go?

Block Health Center, District Hospital,

Nursing Home, Private Doctor,

Village Quack, Other\}

Name 3 public goods your village lacked

\{Water, Education, Health, Transport,

for the last 3 years

Road, Drainage, No Problems,

Don't Know, Others \}

\{Water, Education, Health, Transport,

Name 3 important public goods

Road, Drainage, No Problems,

Don't Know, Others\}

Do you think of yourself as an Indian?

\{Yes, No, Indifferent, Don't know,

I belong to this village/district\}

Do you think of yourself as a Hindu/Muslim? \{Yes, No, Indifferent, Don't know

Do you believe you belong to this village? $\quad$ YYes, No, Indifferent, Don't know

If a close relative married a non-hindu/ \{Good, Bad,

non-muslim, how would you feel?

Indifferent, Not Bad, Don't know\}

If your neighbor belongs to a different religion, \{I like, I don't like, It's normal,

how would you feel? Do not dislike, Indifferent,

We do not mix, Don't know

(Hindus only) If your neighbor belongs to a $\quad$ I like, I don't like, It's normal,

different caste, how would you feel? Do not dislike, Indifferent,

We do not mix, Don't know

Would you like children from other religions

$\{$ Few, $<$ half, Half,

in your child's school?

$>$ Half, Almost everyone,

I don't like children from other

religions in school,

Better everyone studies together, 
Don't know

In your village, how many are of your religion? \{Few, $<$ Half, Half, $>$ Half,

Almost everyone, Don't know

In today's session, was there any person from $\quad\{$ Few, $<$ Half, Half, $>$ Half,

your religion or other religion whom you

Almost everyone, Don't know

personally knew?

Table 5: Post-experimental questions 